\title{
Heterostructured Electrocatalysts for Hydrogen Evolution Reaction Under Alkaline Conditions
}

\author{
Jumeng Wei ${ }^{1,2} \cdot$ Min Zhou $^{2} \cdot$ Anchun Long ${ }^{2} \cdot$ Yanming Xue $^{3} \cdot$ Hanbin Liao ${ }^{4,5}$ Chao Wei ${ }^{4,5} \cdot$ Zhichuan J. Xu $^{4,5,6,7}$
}

Received: 20 August 2018/Accepted: 21 October 2018/Published online: 7 November 2018

(C) The Author(s) 2018

\section{Highlights}

- Heterostructured catalysts offer improved HER activities in alkaline solutions due to their fascinating synergistic effects on the heterogeneous interfaces.

- Representative heterostructured HER catalysts for alkaline media are summarized.

- Acceleration of the Volmer step, crucial for alkali-active catalysts, is highlighted.

\begin{abstract}
The hydrogen evolution reaction (HER) is a half-cell reaction in water electrolysis for producing hydrogen gas. In industrial water electrolysis, the HER is often conducted in alkaline media to achieve higher stability of the electrode materials. However, the kinetics of the HER in alkaline medium is slow relative to that in acid because of the low concentration of protons in the former. Under the latter conditions, the entire HER process will require additional effort to obtain protons by water dissociation near or on the catalyst surface. Heterostructured catalysts, with fascinating synergistic effects derived from their heterogeneous interfaces, can provide multiple functional sites for the overall reaction process. At present, the activity of the most active known heterostructured catalysts surpasses (platinum-based heterostructures) or approaches
\end{abstract}

Min Zhou

minzhou@yzu.edu.cn

$\triangle$ Yanming Xue

ym.xue@hebut.edu.cn

$\triangle$ Zhichuan J. Xu

xuzc@ntu.edu.sg

1 College of Chemistry and Materials Engineering, Anhui Science and Technology University, Bengbu 233100, People's Republic of China

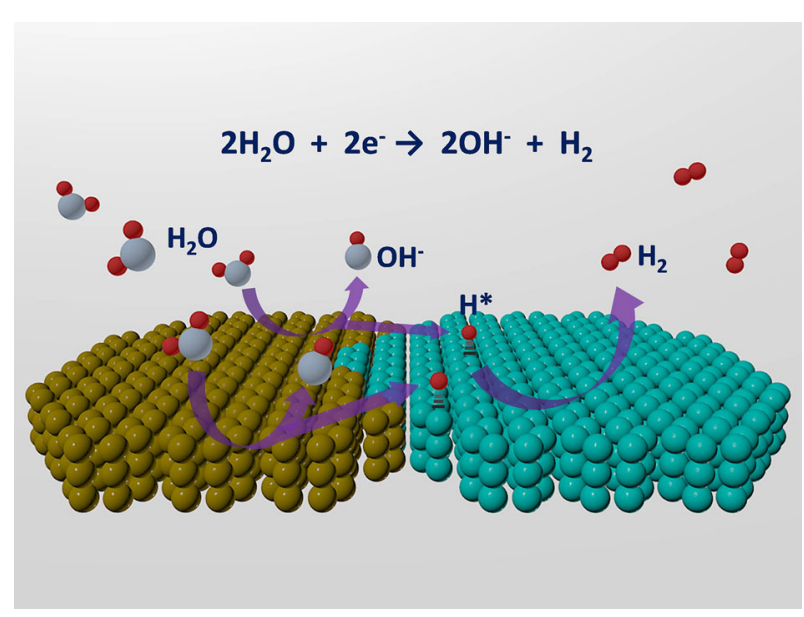

2 College of Physical Science and Technology, and Institute of Optoelectronic Technology, Yangzhou University, Yangzhou 225002, People's Republic of China

3 School of Materials Science and Engineering, Hebei University of Technology, Tianjin 300130, People's Republic of China

4 School of Materials Science and Engineering, Nanyang Technological University, 50 Nanyang Avenue, Singapore 639798, Singapore 
(noble-metal-free heterostructures) that of the commercial $\mathrm{Pt} / \mathrm{C}$ catalyst under alkaline conditions, demonstrating an infusive potential to break through the bottlenecks. This review summarizes the most representative and recent heterostructured HER catalysts for alkaline medium. The basics and principles of the HER under alkaline conditions are first introduced, followed by a discussion of the latest advances in heterostructured catalysts with/without noblemetal-based heterostructures. Special focus is placed on approaches for enhancing the reaction rate by accelerating the Volmer step. This review aims to provide an overview of the current developments in alkaline HER catalysts, as well as the design principles for the future development of heterostructured nano- or micro-sized electrocatalysts.

Keywords Hybrid catalyst - Hydrogen production · Water splitting · Interface engineering · Synergistic effect

\section{Introduction}

The ever-increasing demands for energy have led to the massive consumption of fossil fuels worldwide, with accompanying concerns about their limited reserves and serious environmental issues. During the past decades, alternative energy resources, including solar, wind, and hydroelectric power, have been considered as clean and sustainable alternatives to fossil fuels. However, the utilization of these clean energy resources is restricted by their uneven spatial and temporal distribution; hence, highly efficient technologies for energy storage and conversion are desired. Hydrogen, an eco-friendly fuel with high energy density, is recognized as a promising medium for storage of the energy from these sustainable resources $[1,2]$. Thus, the acquisition of hydrogen via a low-cost and highly efficient route is a significant issue and has long been studied.

To date, the main route for industrial hydrogen production is the electrolysis of water in alkaline solution, which involves the hydrogen evolution reaction (HER) on the cathode and the oxygen evolution reaction (OER) on

5 The Cambridge Centre for Advanced Research and Education in Singapore, 1 CREATE Way, Singapore 138602, Singapore

6 Solar Fuels Laboratory, Nanyang Technological University, 50 Nanyang Avenue, Singapore 639798, Singapore

7 Energy Research Institute @ Nanyang Technological University, 50 Nanyang Avenue, Singapore 639798, Singapore the anode within an electrolyzer [3, 4]. The water splitting efficiency depends on the catalytic activity of the electrocatalysts utilized on both electrodes [5-8]. Specifically, the HER in alkaline solution suffers from relatively slow kinetics compared to that in acidic solution, thus requiring a high overpotential to drive the reaction [9-12]. Further, the alkaline HER is also a key step in the chlor-alkali process, a widely applied but energy-intensive practice. Therefore, the design and fabrication of high-performance HER catalysts for alkaline medium are undertakings of great significance for reducing energy consumption.

The sluggish reaction rate of the HER in alkaline solution originates from the additional water dissociation step that provides protons for the subsequent reactions, but this step does not occur in acidic solution. Generally, in alkaline medium, the HER proceeds through two steps: First, the catalyst cleaves a $\mathrm{H}_{2} \mathrm{O}$ molecule into a hydroxyl ion $\left(\mathrm{OH}^{-}\right)$and an adsorbed hydrogen atom $\left(\mathrm{H}_{\mathrm{ads}}\right.$, Volmer step), and then a hydrogen molecule detaches via either the interaction of the $\mathrm{H}$ atom and water molecule (Heyrovsky step), or the combination of two $\mathrm{H}$ atoms (Tafel step). The catalyst should facilitate the reactions in both steps, each of which involves diverse adsorbed intermediates, making optimization of the catalytic activity difficult [11]. Even for the most prominent catalyst, $\mathrm{Pt}$, the catalytic activity in alkaline medium is hindered by the sluggish water dissociation step, resulting in a reaction rate that is 2-3 orders of magnitude lower than that in acidic solution [11, 13, 14]. Though much effort has been expended in this research area, there is an emerging desire from academics to industry to enhance the catalytic performance of the stateof-the-art catalysts for the alkaline HER.

Recently, heterostructured materials, especially those on the nanoscale, have exhibited great potential in this area and drawn particular attention from researchers. These classes of catalysts, with double or multiple types of active sites on the surface, exhibit remarkable advantages for the HER in alkaline solutions. For instance, in $\mathrm{Pt} / \mathrm{Ni}(\mathrm{OH})_{2}$ heterostructured catalysts, $\mathrm{Ni}(\mathrm{OH})_{2}$ provides active sites for cleaving the $\mathrm{H}-\mathrm{OH}$ bonds, while Pt facilitates combination of the generated hydrogen intermediates to form $\mathrm{H}_{2}$ molecules [15]. This type of bicomponent material displays significantly enhanced catalytic activity compared to those of the corresponding unitary components. In addition, each building block in these heterostructured catalysts is adjustable, allowing for the study of a large number of combinations. Moreover, an electronic effect between the two components at the interface of the heterostructures has been revealed, which may play a crucial role in modifying the electronic structure of the monomers and thus provide more possibilities for tuning the catalytic performance of the alkaline HER. 
Although many reported heterostructured catalysts have demonstrated enhanced catalytic activity, there still are many drawbacks from the heterostructural combination. For example, the heterostructured catalysts still display limited catalytic performance as their active sites are merely localized on the limited interfaces of the two components [14, 16]. Besides, though improvement on either part of the heterostructure leads to a promotion of the catalytic activity, identification of the key component that relates to the rate-determining step has not been achieved, and no guidelines for designing such catalysts have been established. Moreover, because of the high price and limited reserves of $\mathrm{Pt}$, some non-noble-metal-based heterostructures have been explored as low-cost HER catalysts [17]. However, there is an obvious gap between the catalytic performance of Pt-based and noble-metal-free catalysts. Therefore, to address these issues, several strategies for fabricating various types of heterostructured catalysts on the nanoscale have been adopted. Thus, summarizing the recent advances in the design and fabrication of advanced heterostructured catalysts is of significance for developing better catalysts.

In this review, the basics and principles of the HER under alkaline conditions are first introduced. Heterostructured catalysts for alkaline HER are then discussed in terms of noble-metal-based heterostructured catalysts and non-noble-metal-based heterostructured catalysts. In addition, several emerging strategies for expediting the Volmer step in alkaline media are summarized. This review article aims to provide an overview of the mechanisms of activity promotion for heterostructured catalysts and the corresponding syntheses. The popular design principles summarized herein may help readers to further develop their own multifunctional electrocatalysts, as well as new nanosized catalyst design strategies, for the alkaline HER.

\section{Basics and Principles for HER Under Alkaline Conditions}

The HER is a two-electron transfer reaction, in which active catalysts are required to reduce the energy barriers in each step. The generally accepted pathways for the HER in acidic solution are associated with the adsorption/desorption of a hydrogen intermediate $\left(\mathrm{H}^{*}\right)$ through either the Volmer-Heyrovsky or the Volmer-Tafel mechanism [11-13]:

Volmer step: $\mathrm{H}^{+}+\mathrm{e}^{-} \rightarrow \mathrm{H}^{*}$

Heyrovsky step: $\mathrm{H}^{*}+\mathrm{H}^{+}+\mathrm{e}^{-} \rightarrow \mathrm{H}_{2}$

Tafel step: $\mathrm{H}^{*}+\mathrm{H}^{*} \rightarrow \mathrm{H}_{2}$
In alkaline medium, the reaction formula for the HER is represented as:

Volmer step: $\mathrm{H}_{2} \mathrm{O}+\mathrm{e}^{-} \rightarrow \mathrm{H}^{*}+\mathrm{OH}^{-}$

Heyrovsky step: $\mathrm{H}_{2} \mathrm{O}+\mathrm{e}^{-}+\mathrm{H}^{*} \rightarrow \mathrm{H}_{2}+\mathrm{OH}^{-}$

Tafel step: $\mathrm{H}^{*}+\mathrm{H}^{*} \rightarrow \mathrm{H}_{2}$

The pathways for the HER under acidic and alkaline conditions are illustrated in Scheme 1. In general, the energy required to drive the overall reaction differs based on the reaction pathways involved, where the pathways have different energy barriers. In fact, catalysts display obviously lower activity and exchange current densities in alkaline solution than in acidic solution [18, 19]. For example, the experimentally obtained reaction rate for the HER with $\mathrm{Pt}$ in alkaline medium is two or three orders of magnitude lower than that under acidic conditions. This is likely caused by the initial water dissociation process in the Volmer step of the alkaline HER, which supplies $\mathrm{H}^{*}$ to the following steps by cleaving the $\mathrm{H}-\mathrm{O}-\mathrm{H}$ bond, and is considered to be the ratedetermining step of the overall reaction.

Although the catalytic activity of HER catalysts strongly depends on the $\mathrm{pH}$ of the electrolyte, the underlying mechanisms are still under debate [20]. Conway et al. $[21,22]$ investigated the effects of underpotential- (UPD) and overpotential-deposited (OPD) $\mathrm{H}$ on the $\mathrm{Pt}$ surface based on the 'volcano relation' between the exchange current density and the bond energy of $\mathrm{H}$ chemisorbed on the metal or the standard Gibbs energies of chemisorption of $2 \mathrm{H}$ from $\mathrm{H}_{2}$. They found that the kinetically significant intermediate adsorbed on Pt and related metals in the HER is the weakly bound OPD $\mathrm{H}$ rather than the strongly bound UPD-type of $\mathrm{H}$. The more the OPD $\mathrm{H}$, the higher the activity. The OPD $\mathrm{H}$ coverage is much lower in alkaline than acidic solutions, making the discharge step (Volmer step) the rate-controlling step in alkaline solution, which results in a slower reaction rate. Lately, Yan et al. [23] have proposed that the activity of a catalyst for the HER relies solely on the H-binding energy (HBE) of the electrocatalysts, which is sensitive to the $\mathrm{pH}$ of the electrolyte. In an electrolyte with a higher $\mathrm{pH}$, the $\mathrm{HBE}$ of the catalyst is larger, thus resulting in slower reaction kinetics of the HER in base. Nevertheless, further understanding of how the $\mathrm{pH}$ affects the HBE has not been achieved. Moreover, this model is inadequate for interpreting the catalytic behavior on well-defined single-crystal surfaces, such as Pt (111) surfaces [24]. In contrast, Koper and Markovic et al. insisted that the catalytic activity is not solely associated with the HBE; other factors, such as adsorption of the hydroxyl $\left(\mathrm{OH}^{*}\right)$ intermediate, need to be taken into account [25-27]. Either way, a detailed explanation on the atomic and molecular level is desired to address this issue. 


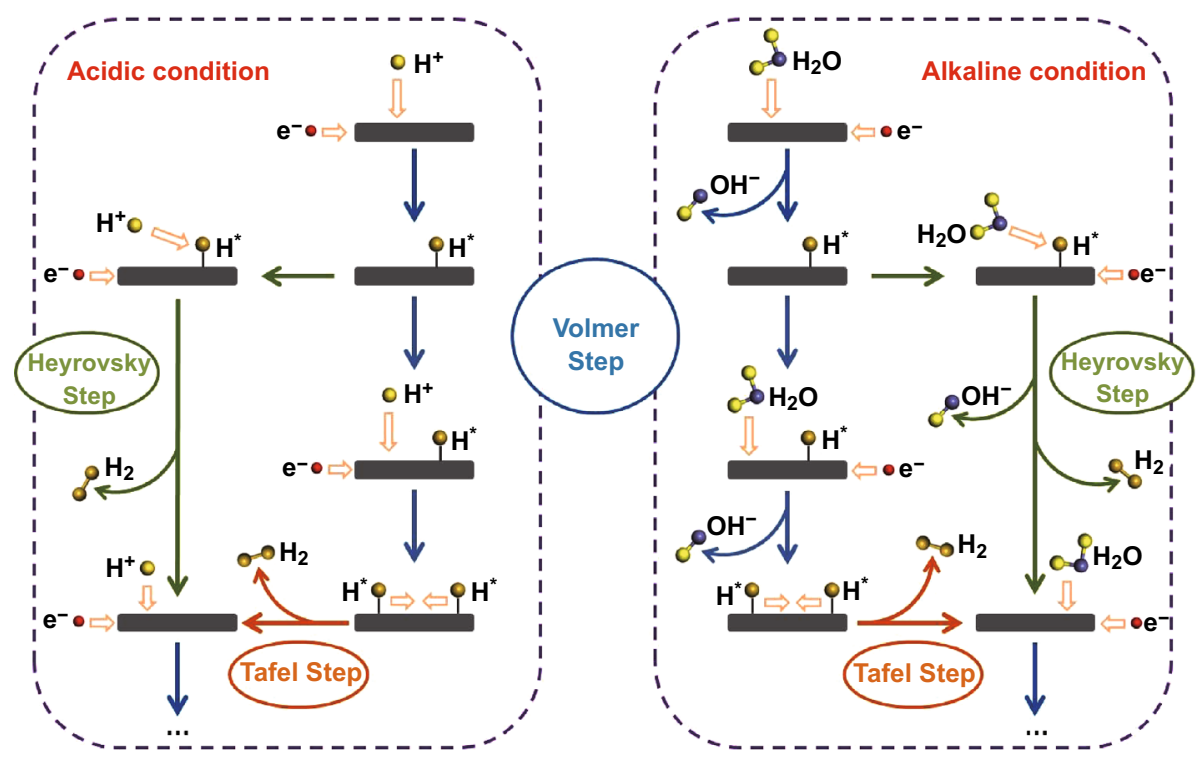

Scheme 1 Schematic pathways for hydrogen evolution reaction under acidic and alkaline conditions

Despite the controversies mentioned above, practical strategies have been developed to promote the HER performance in alkaline solutions. Alloying of transition metals has been found to be an effective route for enhancing the activity of catalysts for the alkaline HER. In the 1980s, Brown and Aruraj et al. investigated the activity of nickel-based binary and ternary alloy catalysts for the HER, where the nickelmolybdenum alloy outperformed the congeners in alkaline medium [28, 29]. Most recently, benefitting from the optimization of the microstructure and composites, $\mathrm{Ni}_{4} \mathrm{Mo}$ nanoparticles exhibited excellent catalytic activity, comparable to that of the commercial $\mathrm{Pt} / \mathrm{C}$ catalyst [30-32]. However, due to the dissolution of metallic molybdenum under the intermittent electrolyzing conditions in alkaline solution, the practical application of such alloys is limited by their poor stability. On the other hand, heterostructured nanomaterials have drawn much attention in this area. Markovic's group first deposited nickel hydroxide nanoclusters on a Pt electrode and demonstrated a sevenfold enhancement of the HER catalytic activity in $1 \mathrm{M} \mathrm{KOH}$ solution [15]. Since then, many attempts have been made to fabricate heterostructured catalysts, aiming to construct ideal candidates that minimize or circumvent the use of noble metals and exhibit improved HER catalytic performance, as discussed hereinafter.

\section{Heterostructured Electrocatalysts for Alkaline HER}

\subsection{Noble-Metal-Based Heterostructured Catalysts}

As discussed, the alkaline HER involves two steps, i.e., the water dissociation step to produce adsorbed $\mathrm{H}^{*}$, and the generation of $\mathrm{H}_{2}$ via either the Heyrovsky or the Tafel step. The commercial Pt catalyst has been found ineffective for accelerating the water dissociation step, though it is a welldocumented active material for the latter. In 2011, Markovic et al. designed a composite material by depositing ultrathin $\mathrm{Ni}(\mathrm{OH})_{2}$ clusters on a $\mathrm{Pt}$ electrode, wherein $\mathrm{Ni}(\mathrm{OH})_{2}$ provides the active sites for water dissociation and Pt facilitates the adsorption of atomic hydrogen and subsequent desorption of the formed $\mathrm{H}_{2}$ [15]. Benefitting from the synergistic effect between the two components, this heterostructured catalyst displayed enhanced catalytic activity (by a factor of $\sim 7$ ) for the HER in $\mathrm{KOH}$ solution, compared to the pristine Pt surface catalyst (Fig. 1). Moreover, the performance of the $\mathrm{Pt} / \mathrm{Ni}(\mathrm{OH})_{2}$ composite was further improved by introducing solvated $\mathrm{Li}^{+}$ions into the compact portion of the double layer, promoting the efficiency of the water dissociation step.

Because the HER takes place on the interfaces of the heterostructures, enlarging the interface density is a reasonable route for providing more active sites and improving the catalytic performance. Huang's group prepared a $\mathrm{NiO}_{x} / \mathrm{Pt}-\mathrm{Ni}$ heterostructure by annealing metallic $\mathrm{Pt}-\mathrm{Ni}$ nanowires in air, during which the segregated $\mathrm{Ni}$ in the $\mathrm{Pt}-$ $\mathrm{Ni}$ alloy was oxidized into $\mathrm{NiO}_{x}$ shells that aggregated on the exterior surface of the nanowires [33]. The density of $\mathrm{NiO}_{x}$ could be controlled by tuning the $\mathrm{Ni}$ content of the precursors and should be neither too low, nor too high in order to maximize the interface between the two components. By using $\mathrm{Pt}_{3} \mathrm{Ni}$ nanowires as a precursor, $\mathrm{NiO}_{x} / \mathrm{Pt}_{3} \mathrm{Ni}$ with a proper $\mathrm{NiO}_{x}$ density was obtained and furnished higher HER activity than commercial $\mathrm{Pt} / \mathrm{C}$ in $0.1 \mathrm{M}$ and $1 \mathrm{M} \mathrm{KOH}$. Subsequently, they constructed a $\mathrm{Pt}_{3} \mathrm{Ni}_{2} / \mathrm{NiS}$ interface nanowire by sulfurization of the composition- 

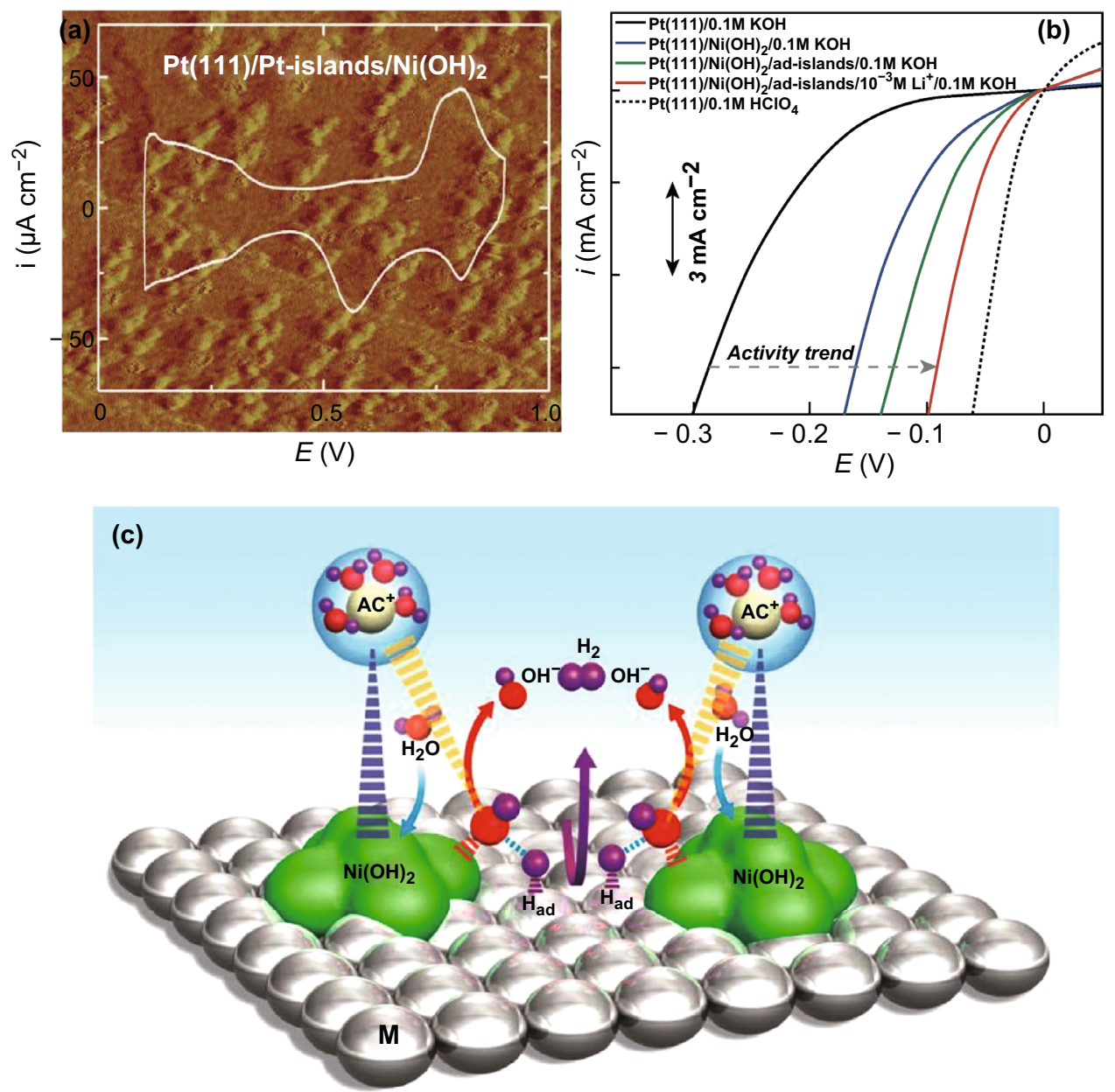

Fig. 1 a STM image $(60 \mathrm{~nm} \times 60 \mathrm{~nm})$ and $\mathrm{CV}$ trace of the $\mathrm{Pt} / \mathrm{Ni}(\mathrm{OH})_{2}$ surface. b Comparison of HER activities of $\mathrm{Ni}(\mathrm{OH})_{2}-\mathrm{modified} \mathrm{Pt}$ electrode and control samples in $0.1 \mathrm{M} \mathrm{KOH}$. c Schematic representation of water dissociation, formation of $\mathrm{M}-\mathrm{H}_{\mathrm{ad}}$ intermediates, and subsequent recombination of two $\mathrm{H}_{\mathrm{ad}}$ atoms to form $\mathrm{H}_{2}$ (magenta arrow), as well as $\mathrm{OH}^{-}$desorption from the $\mathrm{Ni}(\mathrm{OH})_{2}$ domains (red arrows) followed by adsorption of another water molecule on the same site (blue arrows). Reproduced with permission of the authors of Ref. [15]. Copyright 2011, American Association for the Advancement of Science. (Color figure online)

segregated Pt-Ni nanowire precursor [34]. The derived sulfide/metallic heterostructure delivered a current density of $37.2 \mathrm{~mA} \mathrm{~cm}{ }^{-2}$ at the overpotential of $70 \mathrm{mV}$ at $\mathrm{pH} 14$, which is over 9.7 times higher than that of the commercial $\mathrm{Pt} / \mathrm{C}$. Density functional theory (DFT) calculations were employed to construct the energy diagram of the reaction. The energy barrier for breaking the $\mathrm{H}-\mathrm{OH}$ bond in water was reduced from $0.89 \mathrm{eV}$ on the Pt (111) surface to $0.32 \mathrm{eV}$ on the NiS (100) surface, whereas the binding energy of hydrogen on $\mathrm{Pt}_{3} \mathrm{Ni}_{2}$ was much smaller and closer to the optimal value than that of $\mathrm{NiS}$. The reaction steps thus preferentially occurred on the sites requiring less energy, leading to much increased HER activity in alkaline solution.

Further studies focused on lowering the Pt content in the heterostructures. Tang et al. reported a hybrid nanomaterial comprising one-dimensional ultrathin $\mathrm{Pt}$ nanowires and single-layered nickel hydroxide (Pt nanowires/SL-
$\left.\mathrm{Ni}(\mathrm{OH})_{2}\right)$ [35]. Control experiments revealed that the unique surface chemistry of the exfoliated single-layered $\mathrm{Ni}(\mathrm{OH})_{2}$ nanosheets profoundly affected the growth of the ultrathin platinum nanowires, with uniform diameters of about $1.8 \mathrm{~nm}$ and a total Pt content of $38.0 \mathrm{wt} \%$ (Fig. 2). This heterostructure delivered a HER current density (normalized relative to the electrochemically active surface areas (ECSAs) of the Pt species) of $2.48 \mathrm{~mA} \mathrm{~cm}^{-2}$ at the overpotential of $70 \mathrm{mV}$ in $1 \mathrm{M} \mathrm{KOH}$, which is almost one order of magnitude higher than that of the commercial $\mathrm{Pt} / \mathrm{C}$ catalyst. Even for the mass-normalized (using Pt species) current density, the HER activity was 4.35 times that of commercial Pt/C. Similarly, Pt nanocrystals with diameters of $\sim 3 \mathrm{~nm}$ were loaded on single-layer $\mathrm{Ni}(\mathrm{OH})_{2}$ nanosheets with a Pt content of $43 \mathrm{wt} \%$, as reported by Jin and coworkers [18]. This nanocomposite, denoted as Pt@2D$\mathrm{Ni}(\mathrm{OH})_{2}$, exhibited a fivefold improvement in the catalytic activity in $0.1 \mathrm{M} \mathrm{KOH}$ and a reduction of up to $130 \mathrm{mV}$ in 
(a)
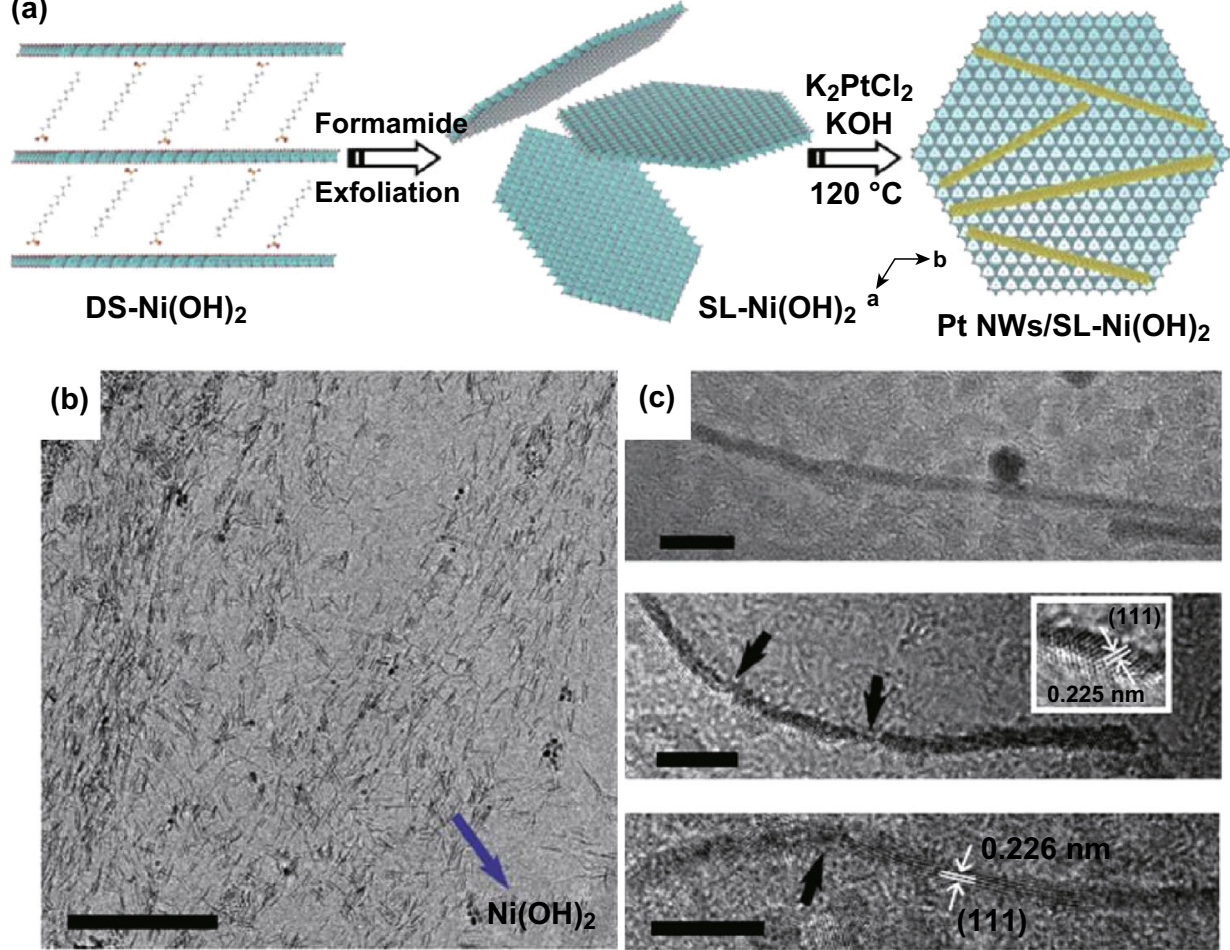

(d)
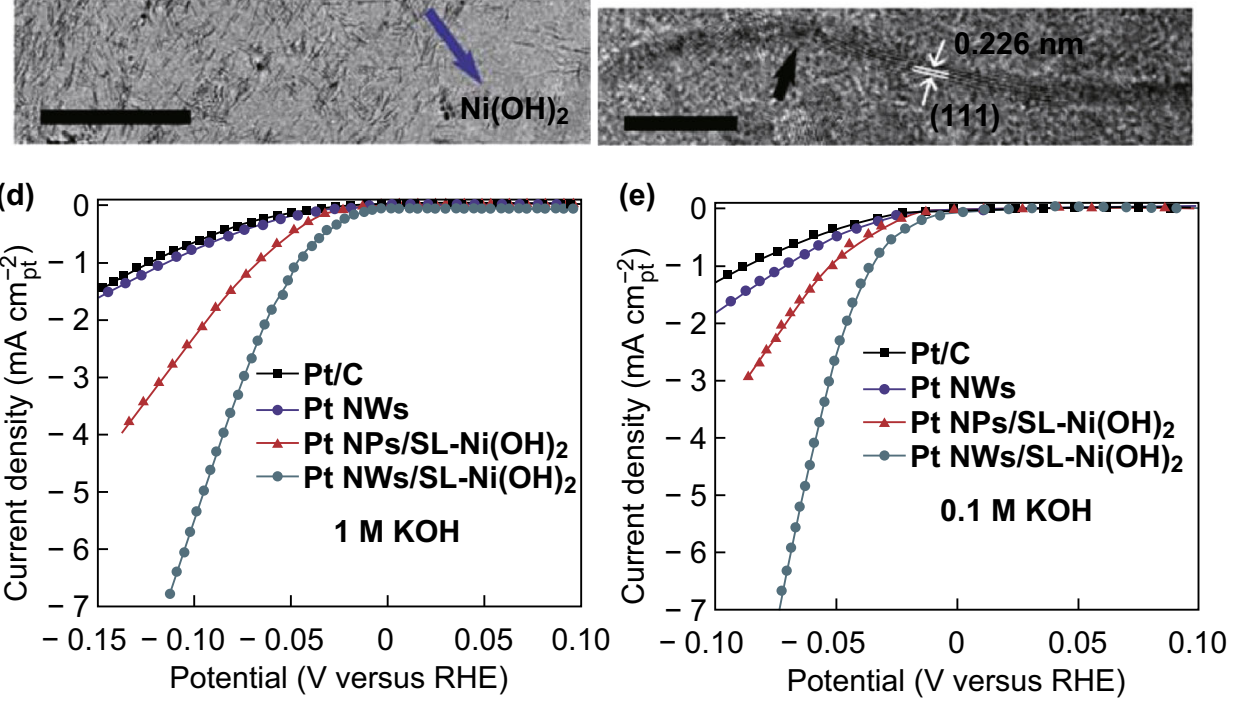

Fig. 2 a Schematic of synthesis of Pt NWs/SL-Ni(OH $)_{2}$. b, $\mathbf{c}$ TEM images of Pt NWs/SL-Ni(OH $)_{2}$; scale bars in $\mathbf{b}$ and $\mathbf{c}$ are 100 and $5 \mathrm{~nm}$, respectively. HER activity of Pt NWs/SL-Ni(OH $\left.)_{2}, \mathrm{Pt} \mathrm{NPs/SL-Ni(OH}\right)_{2}$, pure Pt NWs, and commercial Pt/C $(20 \mathrm{wt} \% \mathrm{Pt})$ in $1 \mathrm{M} \mathrm{d}$ and $0.1 \mathrm{M}$ $\mathrm{KOH}$ e at room temperature. Reproduced with permission of the authors of Ref. [35]. Copyright 2015, Nature Publishing Group

the overpotential compared to commercial $\mathrm{Pt} / \mathrm{C}$. It is proposed that the Pt@2D-Ni(OH $)_{2}$ nanocomposite possesses interfaces with $\mathrm{Pt}-\mathrm{Ni}-\mathrm{OH}$ species under the HER conditions. Such interfaces facilitate both water dissociation and hydrogen recombination and account for the enhanced catalytic activity for water reduction. This group also constructed a $\mathrm{Ni}(\mathrm{OH})_{2}-\mathrm{Pt} / \mathrm{C}$ catalyst, namely the commercial $\mathrm{Pt} / \mathrm{C}$ catalyst modified with single-layer $\mathrm{Ni}(\mathrm{OH})_{2}$ nanosheets [36]. Significantly improved alkaline HER activity was recorded with the deposition of only $20 \mathrm{wt} \%$ single-layer $\mathrm{Ni}(\mathrm{OH})_{2}$ onto the $\mathrm{Pt} / \mathrm{C}$ catalyst. Notably, atomically dispersed noble metal catalysts, also known as single-atom catalysts (SACs), exhibit competitive HER activity with extremely low noble metal contents [37, 38]. Nevertheless, to the best of our knowledge, the synthesis of SACs for the alkaline HER remains rare to date, allowing for more possibility in this promising field.

Nevertheless, due to the formation of Schottky barriers between the heterostructural interfaces, the Pt/hydroxide heterostructures often suffer from relatively low electron transfer ability. Thus, a relatively high overpotential is needed to drive the reaction. In view of this, Zheng and Wang's group presented a Pt-decorated $\mathrm{Ni}_{3} \mathrm{~N}$ nanosheet electrocatalyst for the HER under alkaline conditions [39]. Apart from the synergistic effect between the two components, this hybrid nanostructure also enables high 
electron conductivity without Schottky barrier formation, which is due to the metallic nature of $\mathrm{Ni}_{3} \mathrm{~N}$. As a result, the $\mathrm{Ni}_{3} \mathrm{~N} / \mathrm{Pt}$ composite with a $\mathrm{Pt}$ content of $\sim 15 \mathrm{wt} \%$ exhibited performance ranking among the best for the HER under alkaline conditions, with a current density of $200 \mathrm{~mA} \mathrm{~cm}{ }^{-2}$ at an overpotential of $160 \mathrm{mV}$, a Tafel slope of $36.5 \mathrm{mV} \mathrm{dec}^{-1}$, and excellent stability with $82.5 \%$ current retention after $24 \mathrm{~h}$ of operation. This work provided an effective strategy for further enhancing the catalytic performance of these heterostructured catalysts.

Apart from $\mathrm{Pt}$, other precious metals such as palladium and ruthenium have also been employed in heterostructured catalysts [40, 41]. Xu et al. fabricated a core-shellstructured $\mathrm{Pd} / \mathrm{FeO}_{x}(\mathrm{OH})_{2-2 x}$ composite by electrochemical cycling of the starting $\mathrm{Pd} / \mathrm{Fe}_{3} \mathrm{O}_{4}$ nanoparticles (Fig. 3a-d) [40]. In this hybrid, the Fe species act as additional sites for water dissociation for improving the proton supply, and the Pd surface serves as the hydrogen adsorption/desorption sites (Fig. 3e). Furthermore, they revealed that the HER activity of $\mathrm{Pd} / \mathrm{FeO}_{x}(\mathrm{OH})_{2-2 x}$ depends on the coverage of iron (oxy)hydroxide on the Pd surface, which can be subtly tuned by varying the number of cycles in the electrochemical cycling process. The plot of the intrinsic alkaline HER activity as a function of the $\mathrm{FeO}_{x}(\mathrm{OH})_{2-2 x}$ coverage was characterized by a striking volcano shape (Fig. 3h). The optimized $\mathrm{Pd} / \mathrm{FeO}_{x}(\mathrm{OH})_{2-2 x}$ composite with a $\mathrm{FeO}_{x}(-$ $\mathrm{OH})_{2-2 x}$ coverage of about $40 \%$ displayed a HER activity that was nineteen times greater than that of the plain $\mathrm{Pd}$ nanoparticles (Fig. 3f). In addition, the HER turnover frequency (TOF) of the $\mathrm{Pd} / \mathrm{FeO}_{x}(\mathrm{OH})_{2-2 x}$ composite was $0.50 \mathrm{~s}^{-1}$ atom $^{-1}$ at an overpotential of $150 \mathrm{mV}$, which is twenty-five times higher than that of pure $\mathrm{Pd}\left(0.02 \mathrm{~s}^{-1}\right.$ atom $^{-1}$ ) (Fig. $3 \mathrm{~g}$ ). This strategy is expected to be extendable to optimizing the activity of other multistep catalysis processes on nanosized surfaces.
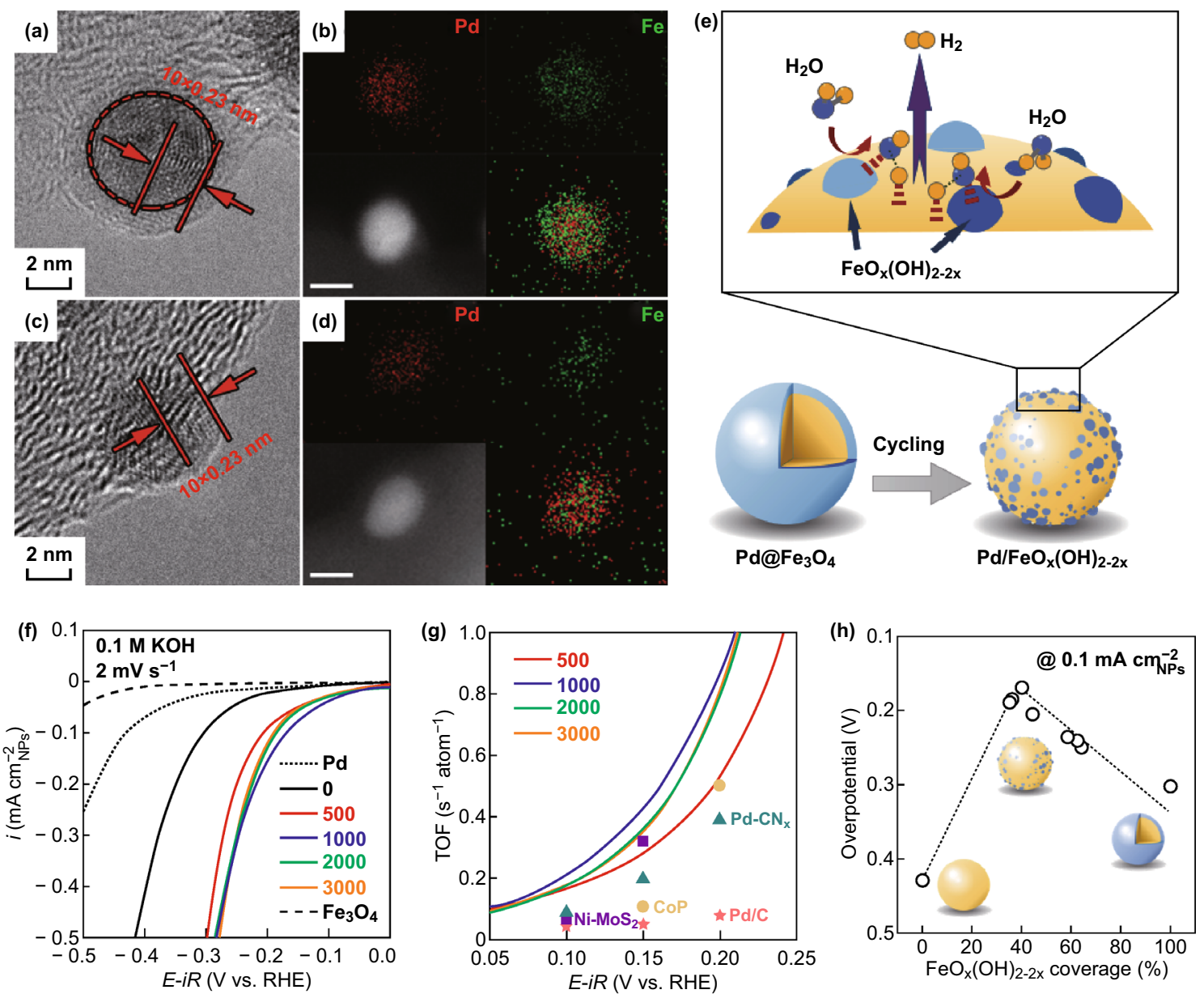

Fig. 3 TEM images and EDS elemental mapping of $\mathrm{Pd} / \mathrm{FeO}_{x}(\mathrm{OH})_{2-2 x} \mathrm{NPs} \mathbf{a}$, $\mathbf{b}$ before cycling and $\mathbf{c}$, $\mathbf{d}$ after 1000 electrochemical cycles. The scale bar is $5 \mathrm{~nm}$. e Schematic diagram of the alkaline HER reaction process on the surface of core/shell Pd/FeO ${ }_{x}(\mathrm{OH})_{2-2 x} \mathrm{nanoparticles}$ after electrochemical cycling. $\mathbf{f} i R$-corrected linear sweep voltammogram (LSV) curves. $\mathbf{g}$ Turnover frequencies $(\mathrm{TOFs})$ of $\mathrm{Pd} / \mathrm{FeO}{ }_{x}(\mathrm{OH})_{2-2 x} \mathrm{NPs}$ and catalysts in the benchmark literature: $\mathrm{Pd} / \mathrm{C}, \mathrm{Pd}-\mathrm{CN}_{x}, \mathrm{Ni}-\mathrm{MoS}_{2}$, and CoP. h HER activity versus $\mathrm{FeO}_{x}(\mathrm{OH})_{2-2 x}$ coverage [40]. Copyright 2017, Wiley-VCH 


\subsection{Non-Noble-Metal-Based Heterostructured Catalysts}

The scarcity and high cost of noble metals restrict their large-scale utilization in catalysis. Therefore, a number of emerging studies have reported the design and development of noble-metal-free catalysts for use under alkaline conditions. In 2014, Dai's group fabricated a NiO/Ni nanohybrid anchored on carbon nanotubes having numerous exposed $\mathrm{NiO} / \mathrm{Ni}$ nanointerfaces [42]. A high HER catalytic activity close to that of commercial $\mathrm{Pt} / \mathrm{C}$ catalysts was achieved in basic solution, exceeding that of the control samples without oxide/metal interfaces. The authors further illustrated the significance of the $\mathrm{NiO} / \mathrm{Ni}$ interface in alkaline HER: The $\mathrm{OH}^{-}$generated by $\mathrm{H}_{2} \mathrm{O}$ splitting preferentially attached to the positively charged $\mathrm{Ni}$ species in $\mathrm{NiO}$, while the nearby metallic Ni sites facilitated $\mathrm{H}$ adsorption to generate $\mathrm{H}_{2}$ on the electrode. The superb HER catalytic activity was therefore attributed to the synergistic effect between the nickel species with different valences. Additionally, the presence of carbon nanotubes afforded the catalyst high conductivity for electron transfer, and rich active sites, by impeding aggregation of the nickel species.

In the past decade, molybdenum disulfide $\left(\mathrm{MoS}_{2}\right)$ has been recognized as a substitute for Pt for acidic HER catalysis due to its adequate ability to adsorb hydrogen species on its edge sites [43]. For the alkaline HER, the catalytic performance of $\mathrm{MoS}_{2}$-based heterostructured catalysts can also be promoted by accelerating the Volmer step. For instance, $\mathrm{Ni}(\mathrm{OH})_{2}$ nanoparticles were electrodeposited on the surface of $\mathrm{MoS}_{2}$ nanosheets that were previously vertically grown on conductive carbon cloth [19]. This hybrid nanostructure exhibited an overpotential of $80 \mathrm{mV}$ at $10 \mathrm{~mA} \mathrm{~cm}{ }^{-2}$ and a Tafel slope of $60 \mathrm{mV} \mathrm{dec}^{-1}$ in $1.0 \mathrm{M} \mathrm{KOH}$ electrolyte, both of which surpassed those of the unitary counterparts. The authors claimed that the increased activity of the hybrid catalyst was ascribed not only to the interfacial cooperation between $\mathrm{Ni}(\mathrm{OH})_{2}$ and $\mathrm{MoS}_{2}$, but also to charge transfer from $\mathrm{Ni}(\mathrm{OH})_{2}$ to $\mathrm{MoS}_{2}$, leading to a more optimal binding energy for the reaction intermediates. In another study, Yang et al. assembled a $\mathrm{MoS}_{2} / \mathrm{NiCo}-\mathrm{layered}$ double hydroxide (LDH) heterostructure as a HER electrocatalyst for use in alkaline electrolyte, where the heterostructure exhibited an extremely low overpotential of $78 \mathrm{mV}$ at $10 \mathrm{~mA} \mathrm{~cm}$ ch $^{-2}$ and a low Tafel slope of $76.6 \mathrm{mV} \mathrm{dec}{ }^{-1}$ in $1 \mathrm{M} \mathrm{KOH}$ solution [44]. For both $\mathrm{MoS}_{2}$ and $\mathrm{MoS}_{2} / \mathrm{NiCo}-\mathrm{LDH}$, the reaction proceeds through a Volmer-Heyrovsky pathway. The activation energy of the Heyrovsky and Volmer steps in the reactions over the $\mathrm{MoS}_{2} / \mathrm{NiCo}-\mathrm{LDH}$ catalyst was much lower than that with bare $\mathrm{MoS}_{2}$, as hybridization accelerates the water dissociation steps in the HER in alkaline environment
(Fig. 4). Long-term stability is another key parameter for evaluating the performance of an electrocatalyst. For instance, Liu's group synthesized a heterostructure, where $\mathrm{Co}(\mathrm{OH})_{2}$ nanoparticles were confined in $\mathrm{MoS}_{2}$ nanosheets [45]. The catalyst displayed a low onset overpotential of $15 \mathrm{mV}$, a small Tafel slope of $53 \mathrm{mV} \mathrm{dec}^{-1}$, and good durability (sustained for $20-\mathrm{h}$ test). Here, the unique sandwich-like structure was considered to prevent the aggregation or loss of $\mathrm{Co}(\mathrm{OH})_{2}$, therefore leading to good stability.

Apart from the intrinsic catalytic activity, the electron transfer ability and the density of active sites in the electrode also impact the catalytic performance. For heterostructured catalysts, such as $\mathrm{MoS}_{2}$ nanosheet-supported $\mathrm{Ni} / \mathrm{Co}$ hydroxides, the catalytic performance is limited by two features: (1) The poor electronic conductivity of $2 \mathrm{H}-\mathrm{MoS}_{2}$ fails to afford fast electron transfer and (2) the number of catalytic sites on $2 \mathrm{H}-\mathrm{MoS}_{2}$ is insufficient as only the edge sites are active for the HER. In light of these considerations, Liang et al. fabricated a $\mathrm{Ni}$ oxyhydroxide/1T-MoS 2 hybrid by in situ growth of Ni oxyhydroxide nanoparticles on $1 \mathrm{~T}-\mathrm{MoS}_{2}$ nanosheets [46]. The optimized catalyst was obtained by tuning the content of the Ni species: A cathodic current density of $10 \mathrm{~mA} \mathrm{~cm}{ }^{-2}$ at an overpotential of $73 \mathrm{mV}$, which is $185 \mathrm{mV}$ less than that of the original $1 \mathrm{~T}-\mathrm{MoS}_{2}$ in $1 \mathrm{M} \mathrm{KOH}$, was achieved. The remarkable activity of this nanohybrid originated from multiple features of the structure: the synergistic effect between Ni oxyhydroxide and $1 \mathrm{~T}-\mathrm{MoS}_{2}$, the metallic nature of $1 \mathrm{~T}-\mathrm{MoS}_{2}$ that facilitates electron transfer, and the active basal planes of $1 \mathrm{~T}-\mathrm{MoS}_{2}$ that dramatically increase the number of catalytic sites.

Nevertheless, $1 \mathrm{~T}-\mathrm{MoS}_{2}$ is neither readily synthesized, nor stable under harsh catalytic conditions due to its metastable nature. Alternatively, $2 \mathrm{H}-\mathrm{MoS}_{2}$ attached to conductive nickel/cobalt sulfides has recently been fabricated. Feng et al. presented a nickel form-supported $\mathrm{MoS}_{2} /$ $\mathrm{Ni}_{3} \mathrm{~S}_{2}$ heterostructure, in which the outer $\mathrm{MoS}_{2}$ nanosheets were decorated on the surface of the inner $\mathrm{Ni}_{3} \mathrm{~S}_{2}$ nanoparticles. In $1 \mathrm{M} \mathrm{KOH}$, the overpotential required to achieve a current density of $10 \mathrm{~mA} \mathrm{~cm}{ }^{-2}$ was approximately $110 \mathrm{mV}$ [47]. Interestingly, this heterostructure also exhibited a low overpotential for the oxygen evolution reaction in the same electrolyte. Employing this $\mathrm{MoS}_{2} /$ $\mathrm{Ni}_{3} \mathrm{~S}_{2}$ heterostructure as a bifunctional electrocatalyst, the resulting alkali electrolyzer delivered a current density of $10 \mathrm{~mA} \mathrm{~cm}^{-2}$ at the very low cell voltage of $1.56 \mathrm{~V}$. An overpotential of $204 \mathrm{mV}$ at current density of $10 \mathrm{~mA} \mathrm{~cm} \mathrm{~cm}^{-2}$ in alkaline solution was also obtained with a $\mathrm{NiS}_{2} / \mathrm{MoS}_{2}$ hybrid synthesized by chemical vapor sulfurization of $\mathrm{NiMoO}_{4}$ nanowires, as reported by $\mathrm{Yu}$ and co-workers [48]. 


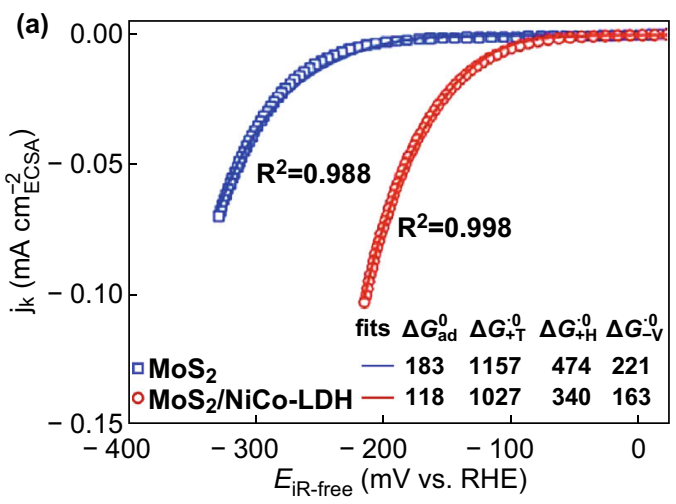

(c)

(b) 600 Dominant Volmer-Heyrovsky pathway
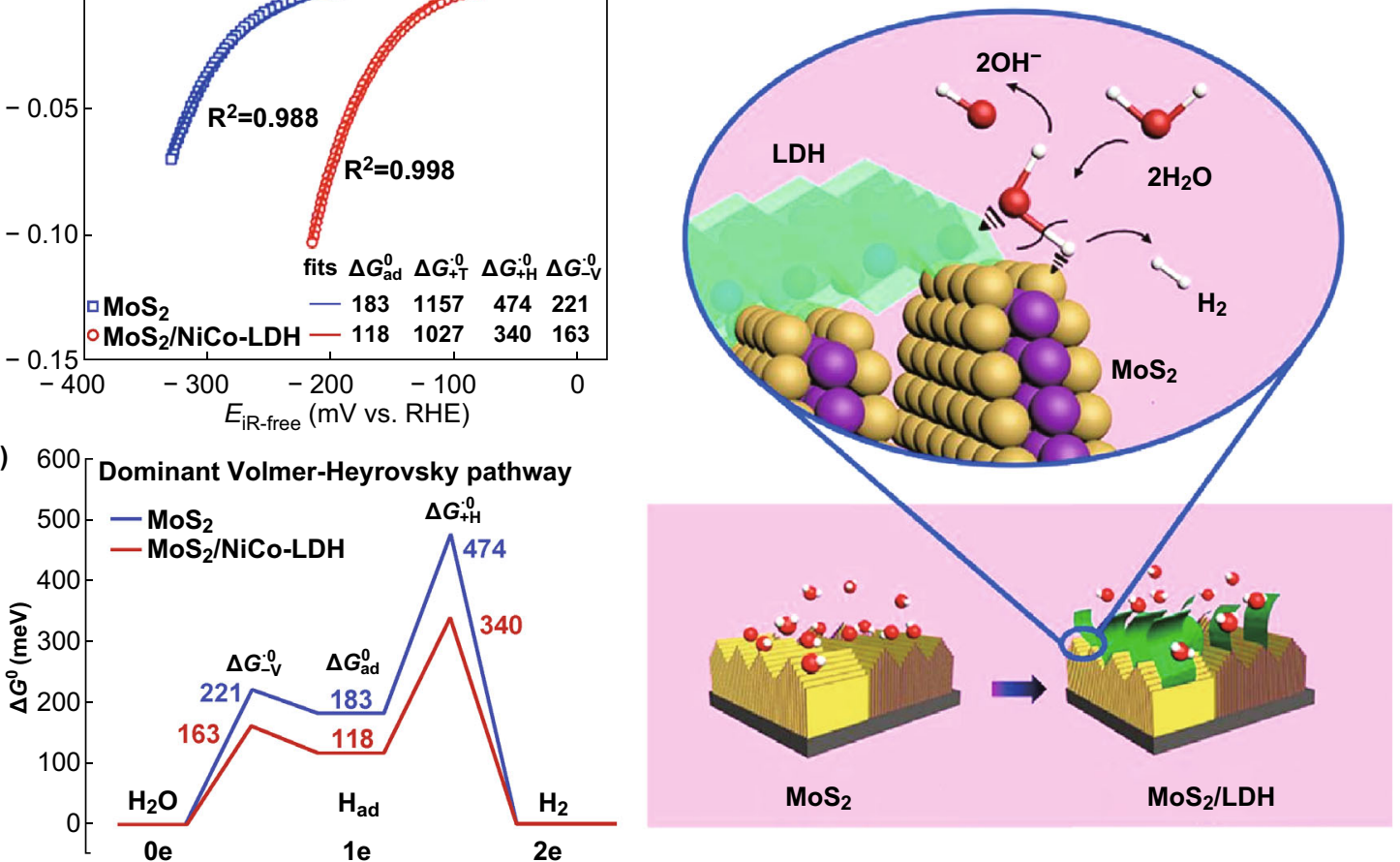

Fig. 4 a ECSA-normalized polarization curves (symbols) of bare $\mathrm{MoS}_{2}$ and $\mathrm{MoS}_{2} / \mathrm{NiCo}-\mathrm{LDH}$ composite catalysts in $1 \mathrm{M} \mathrm{KOH}$ solution with the best fits (lines) using the dual-pathway kinetic model. The fitted standard activation free energies are presented in units of meV. b Free energy diagram of the dominant Volmer-Heyrovsky pathway for HER in alkaline electrolyte for bare $\mathrm{MoS}_{2}$ (blue) and MoS $/ \mathrm{NiCo-LDH} \mathrm{composite}$ (red) catalysts. c Schematic illustration of the $\mathrm{HER}$ at $\mathrm{MoS}_{2} / \mathrm{LDH}$ interface in alkaline environment. Synergistic chemisorption of $\mathrm{H}$ (on $\mathrm{MoS}_{2}$ ) and $\mathrm{OH}$ (on LDH) for enhancing the water dissociation step. Reproduced with permission of the authors of Ref. [44]. Copyright 2017, Cell Press. (Color figure online)

\section{Emerging Strategies for Accelerating the Volmer Step}

Thus far, heterostructured catalysts have shown superior performance in alkaline HER catalysis, as demonstrated by a large number of examples. Theoretically, improvements in both the Volmer step and Heyrovsky/Tafel step should enhance the catalytic efficiency of the overall process. Nevertheless, for the heterostructured catalysts reported so far, the Volmer step was revealed to be the rate-determining step on most of these interfaces [36, 49, 50]. Therefore, accelerating the Volmer step is considered to be a path for directly increasing the catalytic performance [51]. In 2012, after discovering the synergistic effect of the $\mathrm{Pt} / \mathrm{Ni}(\mathrm{OH})_{2}$ heterostructure, Markovic and co-workers investigated the relation between the catalytic activity and the Volmer step for several 3d-M hydroxides (3d-M = Mn, $\mathrm{Fe}, \mathrm{Co}$, and $\mathrm{Ni}$ ) by constructing a series of $\mathrm{Pt} / 3 \mathrm{~d}-\mathrm{M}$ hydroxide hybrids [25]. It was found that the catalytic ability of these heterostructures depends on their affinity for $\mathrm{OH}^{-}$, where strong affinity leads to the accumulation of adsorbed $\mathrm{OH}^{-}$on the surface, thus inhibiting the adsorption of another $\mathrm{H}_{2} \mathrm{O}$ in the following reaction. Based on the experimental results, they proposed the following affinity trend: $\mathrm{Ni}<\mathrm{Co}<\mathrm{Fe}<\mathrm{Mn}$, which is converse to the catalytic activity of the corresponding $\mathrm{Pt} / 3 \mathrm{~d}-\mathrm{M}$ hydroxide hybrids. Nickel hydroxides show the weakest affinity for $\mathrm{OH}^{-}$; thus, the corresponding heterostructure exhibited the best catalytic activity in alkaline solution. This trend was further confirmed for the $1 \mathrm{~T}-\mathrm{MoS}_{2} / 3 \mathrm{~d}-\mathrm{M}$ hydr(oxy)oxide (3d-M $=\mathrm{Fe}, \mathrm{Co}$, and $\mathrm{Ni}$ ) heterostructures, as reported by Liang and co-workers [46]. However, Zhao's group has recently reported a discrepant activity trend. In their research, the monolayer $\mathrm{MoS}_{2}$ nanosheets hybridized with $\mathrm{Co}(\mathrm{OH})_{2}$ exhibited enhanced HER activity compared to that using $\mathrm{Ni}(\mathrm{OH})_{2}$ under identical synthesis and test conditions [52]. Therefore, more effort should be devoted to this point to establish the intrinsic trends in the catalytic ability based on the Volmer step of these 3d-metal hydroxides.

Because nickel hydroxides display favorable water dissociation ability, the role of the Volmer step in the catalytic activity of nickel hydroxides with different polymorphs was investigated by Shi and Ma's group [53]. They prepared $\alpha$ - or $\beta-\mathrm{Ni}(\mathrm{OH})_{2} / \mathrm{Pt}$ hybrids by loading different nickel hydroxides on the surface of a Pt electrode and found that the $\beta-\mathrm{Ni}(\mathrm{OH})_{2} / \mathrm{Pt}$ electrode exhibited superior activity and reaction kinetics for the HER in alkaline media 
(a)
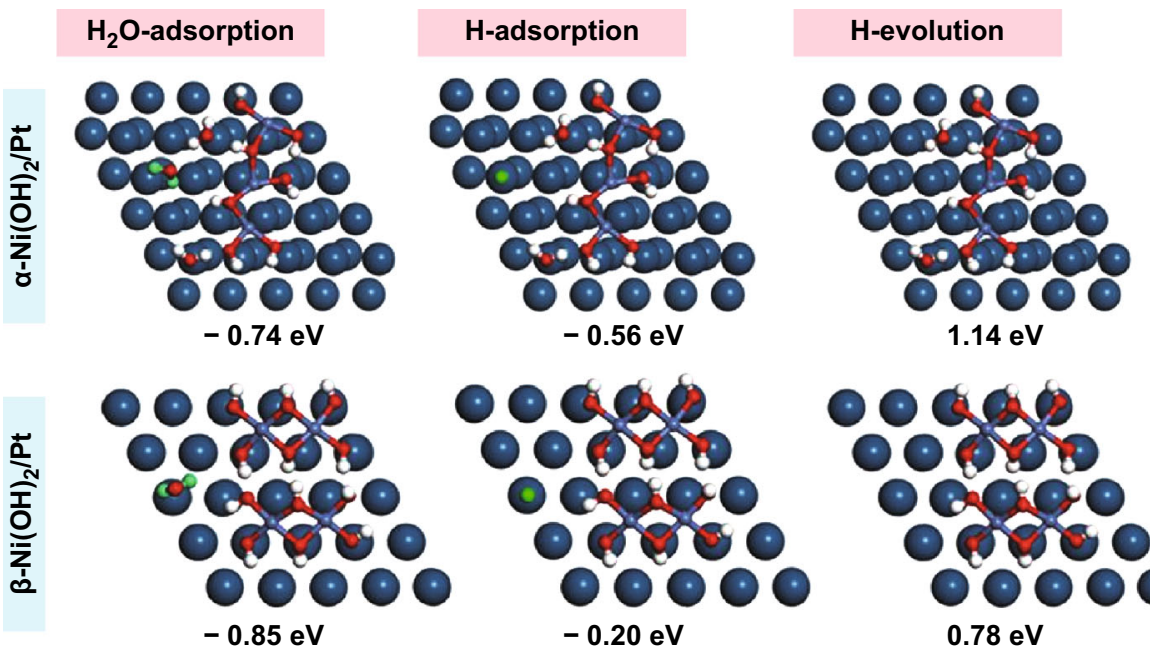

$-0.20 \mathrm{eV}$

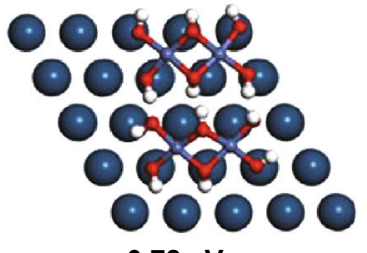

(b)

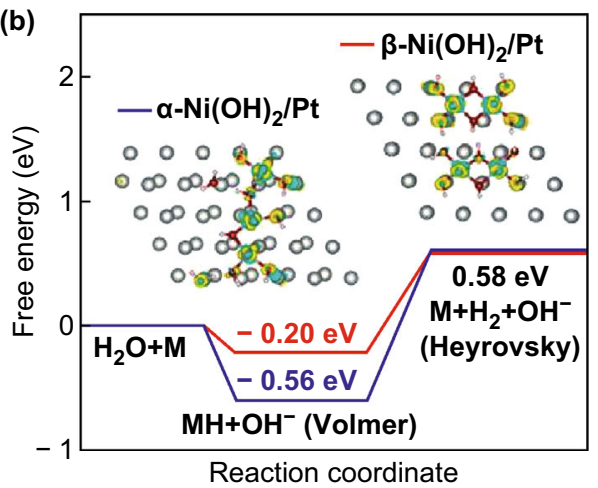

(c)

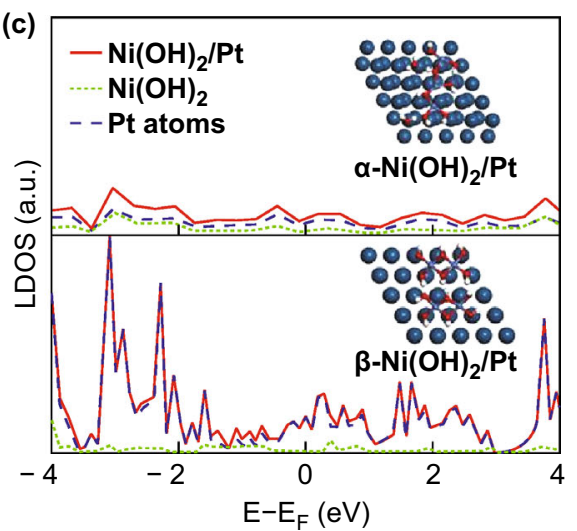

Fig. 5 a Free energies of $\mathrm{H}_{2} \mathrm{O}$ adsorption, $\mathrm{H}$ adsorption, and $\mathrm{H}_{2}$ evolution on $\alpha$ - or $\beta$-Ni(OH $)_{2} / \mathrm{Pt}$ electrode; for clarity, the adsorbed $\mathrm{H}$ atoms for the $\mathrm{H}_{2} \mathrm{O}$ molecules in the top site on the Pt surfaces are colored green. b Adsorption free energy diagram for the Volmer and Heyrovsky steps. c LDOS of the $\alpha$ - or $\beta$-Ni(OH) $2 / \mathrm{Pt}$ electrode. Reproduced with permission of the authors of Ref. [53]. Copyright 2018, American Chemical Society. (Color figure online)

compared to the $\alpha-\mathrm{Ni}(\mathrm{OH})_{2} / \mathrm{Pt}$ electrodes (Fig. 5). On the basis of experimental results and DFT calculations, the superb HER activity of the $\beta-\mathrm{Ni}(\mathrm{OH})_{2} / \mathrm{Pt}$ electrode was ascribed to the structural features of $\beta-\mathrm{Ni}(\mathrm{OH})_{2}$, which possesses a larger interlamellar spacing than $\alpha-\mathrm{Ni}(\mathrm{OH})_{2}$, resulting in more facile access to the sites for adsorbing water molecules and desorbing $\mathrm{OH}^{-}$ions. Interestingly, it was revealed that the interaction between $\beta-\mathrm{Ni}(\mathrm{OH})_{2}$ and $\mathrm{Pt}$ was stronger than that of $\alpha-\mathrm{Ni}(\mathrm{OH})_{2}$. Such an electronic effect provides active sites on the Pt surface with a more suitable binding energy for the $\mathrm{H}$ intermediates. Similar electronic effects were observed between the two components in the $\mathrm{MoS}_{2} / \mathrm{Ni}(\mathrm{OH})_{2}$ and $\mathrm{MoS}_{2} / \mathrm{NiCo}-\mathrm{LDH}$ heterostructures $[19,44]$. Charge transfer from $\mathrm{Ni}(\mathrm{OH})_{2}$ to $\mathrm{MoS}_{2}$ on the $\mathrm{Ni}(\mathrm{OH})_{2} / \mathrm{MoS}_{2}$ interface was confirmed by DFT calculations and led to a more optimal $\Delta G_{\mathrm{H}}$ value of about $-0.06 \mathrm{eV}$ for the $\mathrm{MoS}_{2}$ edge sites, thereby accelerating subsequent $\mathrm{H}_{2}$ generation.
Lately, certain surface modification strategies, such as coating, have been developed to provide satisfactory surfaces for the Volmer step in the alkaline HER. Zhou et al. [54] sought to circumvent the water dissociation step by constructing a polarized carbon surface on $\mathrm{Ni}_{3} \mathrm{~N}$ nanoparticles $\left(\mathrm{Ni}_{3} \mathrm{~N} @ \mathrm{CQDs}\right)$. The researchers created carbon-reinforced $\mathrm{Ni}_{3} \mathrm{~N}$ by dipping $\mathrm{Ni}(\mathrm{OH})_{2}$ in a carbon quantum dot solution and then heating the recovered solids to convert the $\mathrm{Ni}(\mathrm{OH})_{2}$ to $\mathrm{Ni}_{3} \mathrm{~N}$ (Fig. 6). The activation energy of the Volmer step was significantly lowered on the charge-polarized carbon surface, resulting in enhanced catalytic activity, with an overpotential of $69 \mathrm{mV}$ at a current density of $10 \mathrm{~mA} \mathrm{~cm}^{-2}$ in a $1 \mathrm{M} \mathrm{KOH}$ aqueous solution, which is significantly lower than that of the Pt electrode under the same conditions. The carbon coating was also found to protect the interior of the $\mathrm{Ni}_{3} \mathrm{~N}$ layer from oxidation/hydroxylation over hours of continuous use.

Recent studies have also suggested that decoration with copper can alter the electronic structure of 3d-metal-based 

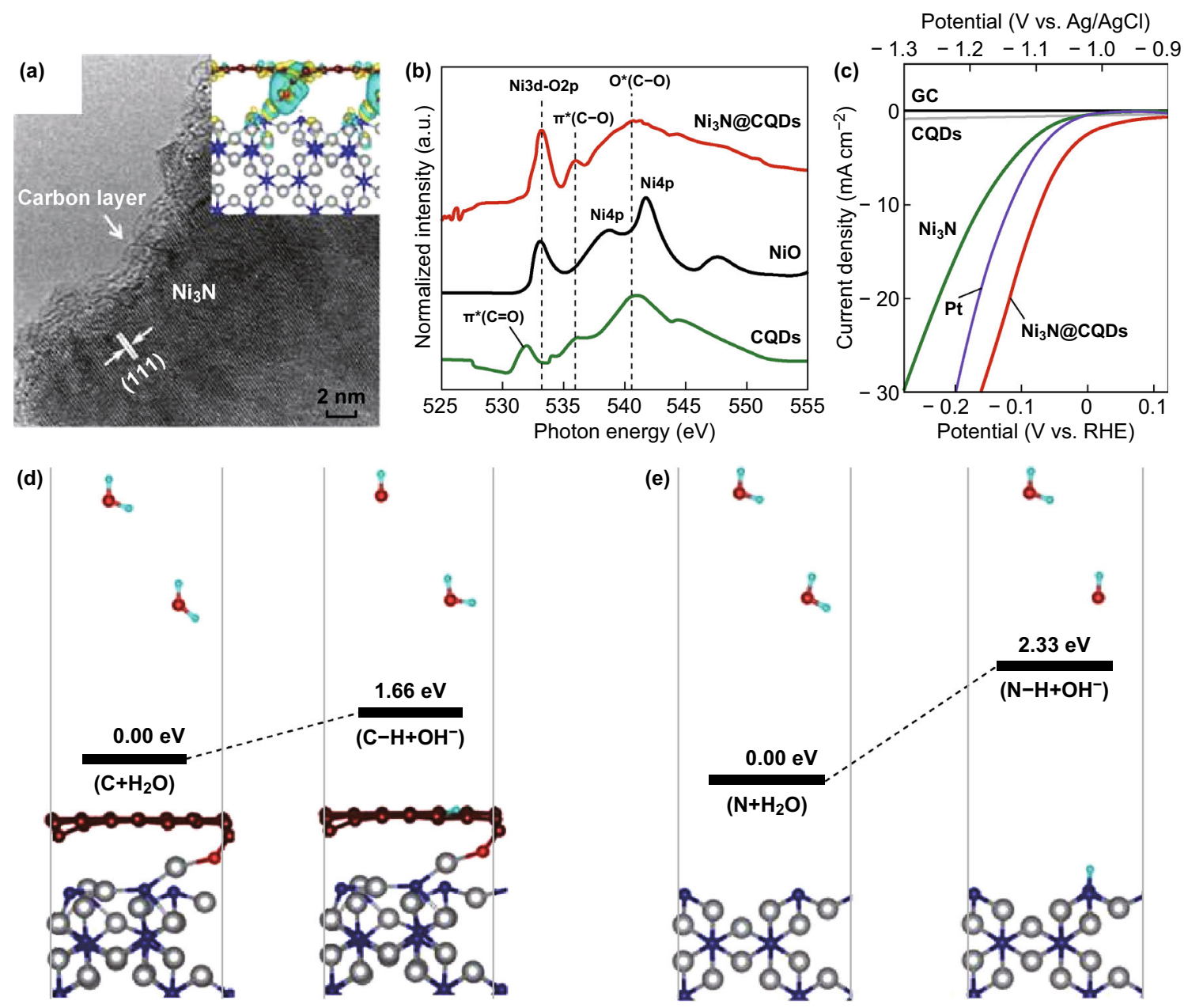

Fig. 6 a High-resolution TEM (HRTEM) image of $\mathrm{Ni}_{3} \mathrm{~N} @ \mathrm{CQDs}$, b O K-edge X-ray absorption near-edge structure (XANES) spectra of $\mathrm{Ni}_{3} \mathrm{~N} @ \mathrm{CQDs}$, commercial $\mathrm{NiO}$ and the CQDs treated in $\mathrm{NH}_{3}$ at $370{ }^{\circ} \mathrm{C}$, $\mathbf{c}$ linear scan voltammetry (LSV) polarization curves of $\mathrm{Ni}_{3} \mathrm{~N} @ \mathrm{CQDs}$ in comparison with those of platinum (Pt) electrode, pristine $\mathrm{Ni}_{3} \mathrm{~N}$, CQDs, and glassy carbon (GC) electrode in a $1 \mathrm{M} \mathrm{KOH}$ aqueous solution. Comparison of HER Volmer reaction step and the resultant binding energies on carbon-coated $\mathrm{Ni}_{3} \mathrm{~N}(110)$ d and pristine $\mathrm{Ni}_{3} \mathrm{~N}(110)$ e surfaces. $\mathrm{N}$, $\mathrm{Ni}, \mathrm{C}, \mathrm{O}$, and $\mathrm{H}$ atoms are indicated by blue, gray, brown, red, and cyan, respectively. Reproduced with permission of the authors of Ref. [54]. Copyright 2018, American Chemical Society. (Color figure online)

materials to facilitate faster kinetics in the Volmer step. Zou's group reported a copper cluster-coupled cobalt sulfide heterostructure [55]. Strong charge redistribution was found to occur at the interface region. Electron transfer from $\mathrm{Co}$ to $\mathrm{Cu}$ led to increased electron density in the $\mathrm{Cu}$ cluster region, along with depletion of the electrons at the interfacial cobalt atom region. The formed positive and negative regions in turn strongly promoted the water dissociation step, further facilitating the surface water splitting reaction kinetics. Similarly, $\mathrm{Li}$ and co-workers synthesized $\mathrm{Cu}$ nanodot-decorated $\mathrm{Ni}_{3} \mathrm{~S}_{2}$ nanotubes as efficient electrocatalysts for the HER in alkaline media [56]. The electronic interaction between $\mathrm{Cu}$ and $\mathrm{Ni}_{3} \mathrm{~S}_{2}$ led to positively charged $\mathrm{Cu}$ and negatively charged $\mathrm{Ni}_{3} \mathrm{~S}_{2}$. The former can effectively adsorb and activate water molecules and promote $\mathrm{H}-\mathrm{O}$ cleavage, while the latter can weaken the $\mathrm{S}-\mathrm{H}_{\mathrm{ads}}$ bonds and thus should enhance $\mathrm{H}$ adsorption and desorption. As a result, this $\mathrm{Cu} / \mathrm{Ni}_{3} \mathrm{~S}_{2}$ hybrid exhibited obviously improved electrocatalytic activity and durability for the HER, such as a low onset overpotential of $60 \mathrm{mV}$, a low overpotential of $128 \mathrm{mV}$ at $10 \mathrm{~mA} \mathrm{~cm}^{-2}$, and excellent durability with a current density increase of only $\sim 3 \%$ at an overpotential of $250 \mathrm{mV}$ over $30 \mathrm{~h}$. These studies provide new strategies for optimizing the energy of adsorption/desorption of the HER intermediates on the surface of catalysts in alkaline media.

\section{Summaries and Perspectives}

Recent trends have highlighted the rational design of heterostructured materials for obtaining highly efficient HER electrocatalysts with intriguing synergistic effects in alkaline solutions. For Pt-based heterostructured catalysts, 
studies have been conducted by either enlarging the interfaces, or lowering the content of $\mathrm{Pt}$ species in the heterostructures, resulting in specific activities superior to that of the benchmark Pt/C catalyst. For noble-metal-free catalysts, Ni/Co hydroxides and $\mathrm{MoS}_{2}$ are the commonly utilized building blocks in the heterostructures, leading to enhanced performance through optimization of the density of the catalytic sites and the electron/mass transfer efficiency of the electrode. In addition, acceleration of the Volmer step via various strategies has been demonstrated to be a straightforward route for achieving improved activity of catalysts for the alkaline HER. Table 1 summarizes recently developed heterostructured catalysts for the HER in alkaline solutions. Note that the recorded activities are affected by many factors, including the noble metal content of the catalysts, the exposed surface area, and the utilization or lack of 3D conductive substrates such as nickel foam and carbon fiber cloth within the electrode $[57,58]$. It should also be noted that it is impossible to compare all of these catalysts in terms of the intrinsic

Table 1 Performance of reported heterostructured catalysts for HER in alkaline medium

\begin{tabular}{|c|c|c|c|c|c|c|c|c|c|}
\hline Catalysts & \multicolumn{2}{|c|}{ Electrolyte } & \multicolumn{2}{|c|}{$\begin{array}{l}\text { Overpotential (current } \\
\text { density by electrode surface } \\
\text { area) }\end{array}$} & \multicolumn{2}{|c|}{$\begin{array}{l}\text { Overpotential (current } \\
\text { density by catalyst surface } \\
\text { area) }\end{array}$} & Pt content & $\begin{array}{l}\text { Tafel slope } \\
\left(\mathrm{mV} \operatorname{dec}^{-1}\right)\end{array}$ & Refs. \\
\hline \multicolumn{10}{|c|}{ Platinum-based heterostructures } \\
\hline $\mathrm{NiO}_{x} / \mathrm{Pt}-\mathrm{Ni}$ & \multicolumn{2}{|c|}{$1 \mathrm{M} \mathrm{KOH} \quad \mathrm{GCE}^{\mathrm{a}}$} & \multicolumn{2}{|c|}{70 mV@19.8 mA cm ${ }^{-2}$} & \multicolumn{2}{|l|}{ N/A } & $15.3 \mu \mathrm{g} \mathrm{cm}^{-2}$ & N/A & {$[33]$} \\
\hline $\mathrm{Pt}-\mathrm{Ni} / \mathrm{NiS}$ & $1 \mathrm{M} \mathrm{KOH}$ & $\mathrm{H} \quad \mathrm{GCE}$ & \multicolumn{2}{|c|}{70 mV@37.2 mA cm ${ }^{-2}$} & \multicolumn{2}{|l|}{ N/A } & $15.3 \mu \mathrm{g} \mathrm{cm}^{-2}$ & N/A & [34] \\
\hline $\begin{array}{l}\text { Pt nanowires/ } \\
\quad \mathrm{SL}-\mathrm{Ni}(\mathrm{OH})_{2}\end{array}$ & \multicolumn{2}{|c|}{$\begin{array}{l}0.1 \mathrm{M} \\
\mathrm{KOH}\end{array}$} & \multicolumn{2}{|c|}{70 mV@25.2 mA cm ${ }^{-2}$} & \multicolumn{3}{|c|}{70 mV@6.31 mA cm ${ }^{-2}$} & N/A & [35] \\
\hline $\begin{array}{l}\text { Pt nanocrystals } \\
\text { @ 2D- } \\
\mathrm{Ni}(\mathrm{OH})_{2}\end{array}$ & $\begin{array}{l}0.1 \mathrm{M} \\
\mathrm{KOH}\end{array}$ & GCE & \multicolumn{2}{|c|}{100 mV@5 mA cm ${ }^{-2}$} & \multicolumn{2}{|l|}{ N/A } & $43 \mathrm{wt} \%$ & 72 & {$[18]$} \\
\hline $\mathrm{Ni}(\mathrm{OH})_{2}-\mathrm{Pt} / \mathrm{C}$ & $\begin{array}{l}0.1 \mathrm{M} \\
\mathrm{KOH}\end{array}$ & GCE & \multicolumn{2}{|c|}{157 mV@5 mA cm ${ }^{-2}$} & \multicolumn{2}{|l|}{ N/A } & $20 \mathrm{wt} \%$ & N/A & [36] \\
\hline $\mathrm{Ni}_{3} \mathrm{~N} / \mathrm{Pt}$ & $1 \mathrm{M} \mathrm{KOH}$ & Ni Foam & \multicolumn{2}{|c|}{$160 \mathrm{mV} @ 200 \mathrm{~mA} \mathrm{~cm}{ }^{-2}$} & \multicolumn{2}{|l|}{ N/A } & $15 \mathrm{wt} \%$ & 36.5 & [39] \\
\hline $\mathrm{Pt}-\mathrm{Co}(\mathrm{OH})_{2}$ & $1 \mathrm{M} \mathrm{KOH}$ & $\begin{array}{l}\text { Carbon } \\
\text { Cloth }\end{array}$ & \multicolumn{2}{|c|}{$32 \mathrm{mV} @ 10 \mathrm{~mA} \mathrm{~cm}{ }^{-2}$} & \multicolumn{2}{|c|}{200 mV@3 mA cm ${ }^{-2}$} & $5.7 \mathrm{wt} \%$ & 70 & [61] \\
\hline $\mathrm{PtO}_{2}-\mathrm{Co}(\mathrm{OH}) \mathrm{F}$ & $\begin{array}{l}0.1 \mathrm{M} \\
\mathrm{KOH}\end{array}$ & Ti mesh & \multicolumn{2}{|c|}{$39 \mathrm{mV} @ 4 \mathrm{~mA} \mathrm{~cm}{ }^{-2}$} & 100 mV@1 & $\mu \mathrm{A} \mathrm{cm}{ }^{-2}$ & $4.8 \mathrm{wt} \%$ & 63 & {$[62]$} \\
\hline $\mathrm{PtO}_{2}-\mathrm{CoOOH}$ & $1 \mathrm{M} \mathrm{KO}$ & Ti mesh & 14 mV@10 m & $\mathrm{cm}^{-2}$ & N/A & & N/A & 39 & {$[63]$} \\
\hline $\begin{array}{l}\mathrm{Pd} / \\
\mathrm{FeO} \\
\end{array}$ & $\begin{array}{l}0.1 \mathrm{M} \\
\mathrm{KOH}\end{array}$ & GCE & 280 mV@5 m & $\mathrm{cm}^{-2}$ & 150 mV@0. & $\mathrm{mA} \mathrm{cm}{ }^{-2}$ & N/A & $131-162$ & [40] \\
\hline Catalysts & & Electrolyte & Substrate & $\begin{array}{l}\text { Overpotenti } \\
\text { density by } \\
\text { surface area }\end{array}$ & $\begin{array}{l}\text { (current } \\
\text { ectrode }\end{array}$ & $\begin{array}{l}\text { Overpotenti } \\
\text { density by c } \\
\text { surface area }\end{array}$ & $\begin{array}{l}\text { (current } \\
\text { talyst }\end{array}$ & $\begin{array}{l}\text { Tafel slope } \\
\left(\mathrm{mV} \operatorname{dec}^{-1}\right)\end{array}$ & Refs. \\
\hline Non-noble-metal- & based hete & rostructures & & & & & & & \\
\hline $\mathrm{NiO} / \mathrm{Ni}-\mathrm{CNT}$ & & $1 \mathrm{M} \mathrm{KOH}$ & GCE & $<100 \mathrm{mV}$ & $10 \mathrm{~mA} \mathrm{~cm}^{-2}$ & 100 mV@0. & $2 \mathrm{~mA} \mathrm{~cm}^{-2}$ & 82 & [42] \\
\hline $\mathrm{Ni}(\mathrm{OH})_{2} / \mathrm{MoS}_{2}$ & & $1 \mathrm{M} \mathrm{KOH}$ & Carbon cloth & 80 mV@10 & $\mathrm{nA} \mathrm{cm}{ }^{-2}$ & N/A & & 60 & [19] \\
\hline $\mathrm{MoS}_{2} / \mathrm{NiCo}-\mathrm{LDH}$ & & $1 \mathrm{M} \mathrm{KOH}$ & $\mathrm{CFP}^{\mathrm{b}}$ & 78 mV@10 & $\mathrm{nA} \mathrm{cm}{ }^{-2}$ & 200 mV@0. & $\mathrm{mA} \mathrm{cm}{ }^{-2}$ & 76.6 & [44] \\
\hline $\mathrm{MoS}_{2}$-confined $\mathrm{C}$ & $(\mathrm{OH})_{2}$ & $1 \mathrm{M} \mathrm{KOH}$ & GCE & 89 mV@10 & $\mathrm{nA} \mathrm{cm}{ }^{-2}$ & N/A & & 53 & [45] \\
\hline $1 \mathrm{~T}-\mathrm{MoS}_{2} / \mathrm{NiOOH}$ & & $1 \mathrm{M} \mathrm{KOH}$ & GCE & 73 mV@10 & $\mathrm{nA} \mathrm{cm}-2$ & N/A & & 75 & [46] \\
\hline $\mathrm{MoS}_{2} / \mathrm{Ni}_{3} \mathrm{~S}_{2}$ & & $1 \mathrm{M} \mathrm{KOH}$ & Ni Foam & 110 mV@1 & $\mathrm{mA} \mathrm{cm} \mathrm{cm}^{-2}$ & N/A & & 83 & [47] \\
\hline $\mathrm{NiS}_{2} / \mathrm{MoS}_{2}$ & & $1 \mathrm{M} \mathrm{KOH}$ & GCE & 204 mV@1 & $\mathrm{mA} \mathrm{cm} \mathrm{cm}^{-2}$ & 204 mV@0. & $\mathrm{mA} \mathrm{cm}{ }^{-2}$ & 65 & [48] \\
\hline $\mathrm{MoSe}_{2} @ \mathrm{Ni}_{0.85} \mathrm{Se}$ & & $1 \mathrm{M} \mathrm{KOH}$ & GCE & 117 mV@1 & $\mathrm{mA} \mathrm{cm}-2$ & 117 mV@2. & $\mu \mathrm{A} \mathrm{cm}^{-2}$ & 66 & [64] \\
\hline $2 \mathrm{D}-\mathrm{MoS}_{2} / \mathrm{Co}(\mathrm{OH})$ & & $1 \mathrm{M} \mathrm{KOH}$ & GCE & 128 mV@1 & $\mathrm{mA} \mathrm{cm} \mathrm{cm}^{-2}$ & 128 mV@0. & $\mathrm{mA} \mathrm{cm}{ }^{-2}$ & 76 & {$[52]$} \\
\hline $\mathrm{Ni}_{3} \mathrm{~N} @ \mathrm{CQDs}$ & & $1 \mathrm{M} \mathrm{KOH}$ & GCE & 69 mV@10 & $\mathrm{nA} \mathrm{cm} \mathrm{cm}^{-2}$ & 69 mV@0.4 & $\mathrm{mA} \mathrm{cm}{ }^{-2}$ & 108 & {$[54]$} \\
\hline $\mathrm{Cu} @ \mathrm{CoS} x$ & & $1 \mathrm{M} \mathrm{KOH}$ & CFP & 134 mV@1 & $\mathrm{mA} \mathrm{cm} \mathrm{cm}^{-2}$ & N/A & & N/A & {$[55]$} \\
\hline $\mathrm{Cu} \mathrm{NDs} / \mathrm{Ni}_{3} \mathrm{~S}_{2}$ & & $1 \mathrm{M} \mathrm{KOH}$ & CFP & 128 mV@1 & $\mathrm{mA} \mathrm{cm} \mathrm{cm}^{-2}$ & 128 mV@6. & $\mu \mathrm{A} \mathrm{cm}-2$ & 76.2 & {$[56]$} \\
\hline
\end{tabular}

${ }^{\mathrm{a}} G C E$ Glassy carbon electrode

${ }^{\mathrm{b}} C F P$ Carbon fiber paper 
activities due to the lack of information on the surface area and catalyst loading.

Although remarkable progress has been achieved in the field of alkaline HER catalysis due to the emergence of heterostructured materials, there is still room for the development of better catalysts. To achieve lower cost, higher stability, and higher efficiency, next-generation catalysts must overcome several limitations. First, although the specific catalytic activity of most Pt-based heterostructures surpasses that of the Pt/C catalysts, no significant reduction in the $\mathrm{Pt}$ content in these materials has been realized to date. The synthesis of single-atom catalysts (SACs) with suitable substrates on the nanoscale or microscale has recently emerged and may provide an avenue for lowering the Pt loading [37, 59]. Thus, the electronic configuration and catalytic activity of Pt-based SACs within different chemical environments have to be identified. Second, in spite of the impressive progress in the development of noble-metal-free heterostructures, thus far, the catalytic performance of these species does not satisfy industrial requirements. In general, catalysts with numerous active sites and favorable ability for electron and mass transfer should offer better catalytic activity [60]. Specifically, for 2D nanocatalysts such as $\mathrm{MoS}_{2}$ nanosheets where the active sites are confined within the edge atoms, precise control of the surface and interface is needed to tune the catalytic performance of these nanosized heterostructures. This represents a material engineering challenge. Third, for most of the heterostructured catalysts, the Volmer step is the rate-determining step in the alkaline HER. However, few strategies focusing on this point have been reported so far. Studies combining experimental results and theoretical calculations should be conducted with the aim of fabricating heterostructured catalysts with acceleration of the Volmer step in the alkaline HER, which may provide more opportunities in the materials research community.

\section{Acknowledgements Dr. M. Zhou and Dr. Y. Xue acknowledge the financial support provided by National Natural Science Foundation of China (Nos. 61301026 and 51802073) and the technical support from Testing Center of Yangzhou University. Dr. J. Wei acknowledges the supports from the Talent Introduction Foundation (No. ZRC2014448) and the Key Discipline Foundation (No. AKZDXK2015A01) of Anhui Science and Technology University. Dr. H. Liao and Dr. C. Wei thank the financial support by the Singapore National Research Foundation under its Campus for Research Excellence And Technological Enterprise (CREATE) program through the Cambridge Center for Carbon Reduction in Chemical Technology (C4T) and eCO2EP programs.}

Open Access This article is distributed under the terms of the Creative Commons Attribution 4.0 International License (http://crea tivecommons.org/licenses/by/4.0/), which permits unrestricted use, distribution, and reproduction in any medium, provided you give appropriate credit to the original author(s) and the source, provide a link to the Creative Commons license, and indicate if changes were made.

\section{References}

1. M.K. Debe, Electrocatalyst approaches and challenges for automotive fuel cells. Nature 486, 43-51 (2012). https://doi.org/10. 1038/nature11115

2. Y. Zheng, Y. Jiao, M. Jaroniec, S.Z. Qiao, Advancing the electrochemistry of the hydrogen-evolution reaction through combining experiment and theory. Angew. Chem. Int. Ed. 54, 52-65 (2015). https://doi.org/10.1002/anie.201407031

3. Y. Yan, T. He, B. Zhao, K. Qi, H. Liu, B.Y. Xia, Metal/covalentorganic frameworks-based electrocatalysts for water splitting. J. Mater. Chem. A 6, 15905 (2018). https://doi.org/10.1039/ C8TA05985C

4. J. Pan, Y.Y. Xu, H. Yang, Z. Dong, H. Liu, B.Y. Xia, Advanced architectures and relatives of air electrodes in $\mathrm{Zn}$-air batteries. Adv. Sci. 5, 1700691 (2018). https://doi.org/10.1002/advs. 201700691

5. J. Zhang, H. Wang, Y. Tian, Y. Yan, Q. Xue et al., Anodic hydrazine oxidation assists energy-efficient hydrogen evolution over a bifunctional cobalt perselenide nanosheet electrode. Angew. Chem. Int. Ed. 57, 7649-7653 (2018). https://doi.org/10. 1002/anie.201803543

6. M. Miao, J. Pan, T. He, Y. Yan, B.Y. Xia, X. Wang, Molybdenum carbide-based electrocatalysts for hydrogen evolution reaction. Chem. Eur. J. 23, 10947-10961 (2017). https://doi.org/10. 1002/chem.201701064

7. L.M. Gandía, R. Oroz, A. Ursúa, P. Sanchis, P.M. Diéguez, Renewable hydrogen production: performance of an alkaline water electrolyzer working under emulated wind conditions. Energy Fuels 21, 1699-1706 (2007). https://doi.org/10.1021/ ef060491u

8. M. Zhou, Q. Weng, X. Zhang, X. Wang, Y. Xue, X. Zeng, Y. Bando, D. Golberg, In situ electrochemical formation of coreshell nickel-iron disulfide and oxyhydroxide heterostructured catalysts for a stable oxygen evolution reaction and the associated mechanisms. J. Mater. Chem. A 5, 4335-4342 (2017). https://doi. org/10.1039/C6TA09366C

9. F. Safizadeh, E. Ghali, G. Houlachi, Electrocatalysis developments for hydrogen evolution reaction in alkaline solutions-a review. Int. J. Hydrogen Energy 40, 256-274 (2015). https://doi. org/10.1016/j.ijhydene.2014.10.109

10. F. Lu, M. Zhou, Y. Zhou, X. Zeng, First-row transition metal based catalysts for the oxygen evolution reaction under alkaline conditions: basic principles and recent advances. Small 13, 1701931 (2017). https://doi.org/10.1002/smll.201701931

11. N. Mahmood, Y. Yao, J.W. Zhang, L. Pan, X. Zhang, J.J. Zou, Electrocatalysts for hydrogen evolution in alkaline electrolytes: mechanisms, challenges, and prospective solutions. Adv. Sci. 5, 1700464 (2018). https://doi.org/10.1002/advs.201700464

12. Z. Yao, J. Yan, V. Anthony, S.Z. Qiao, The hydrogen evolution reaction in alkaline solution: from theory, single crystal models, to practical electrocatalysts. Angew. Chem. Int. Ed. 57, 7568-7579 (2018). https://doi.org/10.1002/anie.201710556

13. M. Gong, D.Y. Wang, C.C. Chen, B.J. Hwang, H. Dai, A mini review on nickel-based electrocatalysts for alkaline hydrogen evolution reaction. Nano Res. 9, 28-46 (2015). https://doi.org/10. 1007/s12274-015-0965-x

14. Z.W. Seh, J. Kibsgaard, C.F. Dickens, I. Chorkendorff, J.K. Nørskov, T.F. Jaramillo, Combining theory and experiment in electrocatalysis: Insights into materials design. Science $\mathbf{3 5 5}$, eaad4998 (2017). https://doi.org/10.1126/science.aad4998

15. R. Subbaraman, D. Tripkovic, D. Strmcnik, K.C. Chang, M. Uchimura, A.P. Paulikas, V. Stamenkovic, N.M. Markovic, Enhancing hydrogen evolution activity in water splitting by 
tailoring $\mathrm{Li}^{+}-\mathrm{Ni}(\mathrm{OH})_{2}-\mathrm{Pt}$ interfaces. Science 334, 1256-1260 (2011). https://doi.org/10.1126/science.1211934

16. H. Yang, C. Wang, F. Hu, Y. Zhang, H. Lu, Q. Wang, Atomicscale Pt clusters decorated on porous $\alpha-\mathrm{Ni}(\mathrm{OH})_{2}$ nanowires as highly efficient electrocatalyst for hydrogen evolution reaction. Sci. China Mater. 60, 1121-1128 (2017). https://doi.org/10.1007/ s40843-017-9035-8

17. J. Mahmood, F. Li, S.M. Jung, M.S. Okyay, I. Ahmad, S.J. Kim, N. Park, H.Y. Jeong, J.B. Baek, An efficient and pH-universal ruthenium-based catalyst for the hydrogen evolution reaction. Nat. Nanotechnol. 12, 441 (2017). https://doi.org/10.1038/nnano. 2016.304

18. L. Wang, Y. Zhu, Z. Zeng, C. Lin, M. Giroux et al., Platinumnickel hydroxide nanocomposites for electrocatalytic reduction of water. Nano Energy 31, 456-461 (2017). https://doi.org/10.1016/ j.nanoen.2016.11.048

19. B. Zhang, J. Liu, J. Wang, Y. Ruan, X. Ji et al., Interface engineering: the $\mathrm{Ni}(\mathrm{OH})_{2} / \mathrm{MoS}_{2}$ heterostructure for highly efficient alkaline hydrogen evolution. Nano Energy 37, 74-80 (2017). https://doi.org/10.1016/j.nanoen.2017.05.011

20. Z. Zeng, K.C. Chang, J. Kubal, N.M. Markovic, J. Greeley, Stabilization of ultrathin (hydroxy)oxide films on transition metal substrates for electrochemical energy conversion. Nat. Energy 2, 17070 (2017). https://doi.org/10.1038/nenergy.2017.70

21. B.E. Conway, L. Bai, Determination of adsorption of OPD $\mathrm{H}$ species in the cathodic hydrogen evolution reaction at $\mathrm{Pt}$ in relation to electrocatalysis. J. Electroanal. Chem. 198, 149-175 (1986). https://doi.org/10.1016/0022-0728(86)90033-1

22. B.E. Conway, G. Jerkiewicz, Relation of energies and coverages of underpotential and overpotential deposited $\mathrm{H}$ at $\mathrm{Pt}$ and other metals to the 'volcano curve' for cathodic $\mathrm{H}_{2}$ evolution kinetics. Electrochim. Acta 45, 4075-4083 (2000). https://doi.org/10.1016/ S0013-4686(00)00523-5

23. W. Sheng, M. Myint, J.G. Chen, Y. Yan, Correlating the hydrogen evolution reaction activity in alkaline electrolytes with the hydrogen binding energy on monometallic surfaces. Energy Environ. Sci. 6, 1509 (2013). https://doi.org/10.1039/c3ee00045a

24. I. Ledezma-Yanez, W.D.Z. Wallace, P. Sebastián-Pascual, V. Climent, J.M. Feliu, M.T.M. Koper, Interfacial water reorganization as a pH-dependent descriptor of the hydrogen evolution rate on platinum electrodes. Nat. Energy 2, 17031 (2017). https:// doi.org/10.1038/nenergy.2017.31

25. R. Subbaraman, D. Tripkovic, K.C. Chang, D. Strmcnik, A.P. Paulikas et al., Trends in activity for the water electrolyser reactions on 3d M(Ni Co, Fe, Mn) hydr(oxy)oxide catalysts. Nat. Mater. 11, 550 (2012). https://doi.org/10.1038/nmat3313

26. T. Bligaard, J.K. Nørskov, S. Dahl, J. Matthiesen, C.H. Christensen, J. Sehested, The Brønsted-Evans-Polanyi relation and the volcano curve in heterogeneous catalysis. J. Catal. 224, 206-217 (2004). https://doi.org/10.1016/j.jcat.2004.02.034

27. G.S. Karlberg, Adsorption trends for water, hydroxyl, oxygen, and hydrogen on transition-metal and platinum-skin surfaces. Phys. Rev. B 74, 153414 (2006). https://doi.org/10.1103/Phys RevB.74.153414

28. D.E. Brown, M.N. Mahmood, M.C.M. Man, A.K. Turner, Preparation and characterization of low overvoltage transition metal alloy electrocatalysts for hydrogen evolution in alkaline solutions. Electrochim. Acta 29, 1551-1556 (1984). https://doi. org/10.1016/0013-4686(84)85008-2

29. I.A. Raj, K.I. Vasu, Transition metal-based hydrogen electrodes in alkaline solution-electrocatalysis on nickel based binary alloy coatings. J. Appl. Electrochem. 20, 32-38 (1990). https://doi.org/ 10.1007/BF01012468

30. Y.Y. Chen, Y. Zhang, X. Zhang, T. Tang, H. Luo, S. Niu, Z.H. Dai, L.J. Wan, J.S. Hu, Self-templated fabrication of $\mathrm{MoNi}_{4} /$ $\mathrm{MoO}_{3-x}$ nanorod arrays with dual active components for highly efficient hydrogen evolution. Adv. Mater. 29, 1703311 (2017). https://doi.org/10.1002/adma.201703311

31. J. Zhang, T. Wang, P. Liu, Z. Liao, S. Liu, X. Zhuang, M. Chen, E. Zschech, X. Feng, Efficient hydrogen production on $\mathrm{MoNi}_{4}$ electrocatalysts with fast water dissociation kinetics. Nat. Commun. 8, 15437 (2017). https://doi.org/10.1038/ncomms15437

32. P.M. Csernica, J.R. McKone, C.R. Mulzer, W.R. Dichtel, H.D. Abruña, F.J. DiSalvo, Electrochemical hydrogen evolution at ordered $\mathrm{Mo}_{7} \mathrm{Ni}_{7}$. ACS Catal. 7, 3375-3383 (2017). https://doi. org/10.1021/acscatal.7b00344

33. P. Wang, K. Jiang, G. Wang, J. Yao, X. Huang, Phase and interface engineering of platinum-nickel nanowires for efficient electrochemical hydrogen evolution. Angew. Chem. Int. Ed. 55, 12859-12863 (2016). https://doi.org/10.1002/anie.201606290

34. P. Wang, X. Zhang, J. Zhang, S. Wan, S. Guo, G. Lu, J. Yao, X. Huang, Precise tuning in platinum-nickel/nickel sulfide interface nanowires for synergistic hydrogen evolution catalysis. Nat. $\begin{array}{lllll}\text { Commun. } & 8, & 14580 & \text { (2017). https://doi.org/10.1038/ }\end{array}$ ncomms 14580

35. H. Yin, S. Zhao, K. Zhao, A. Muqsit, H. Tang, L. Chang, H. Zhao, Y. Gao, Z. Tang, Ultrathin platinum nanowires grown on single-layered nickel hydroxide with high hydrogen evolution activity. Nat. Commun. 6, 6430 (2015). https://doi.org/10.1038/ ncomms 7430

36. L. Wang, C. Lin, D. Huang, J. Chen, L. Jiang, M. Wang, L. Chi, L. Shi, J. Jin, Optimizing the Volmer step by single-layer nickel hydroxide nanosheets in hydrogen evolution reaction of platinum. ACS Catal. 5, 3801-3806 (2015). https://doi.org/10.1021/ cs501835c

37. N. Cheng, S. Stambula, D. Wang, M.N. Banis, J. Liu et al., Platinum single-atom and cluster catalysis of the hydrogen evolution reaction. Nat. Commun. 7, 13638 (2016). https://doi.org/ $10.1038 /$ ncomms 13638

38. J. Deng, H. Li, J. Xiao, Y. Tu, D. Deng et al., Triggering the electrocatalytic hydrogen evolution activity of the inert two-dimensional $\mathrm{MoS}_{2}$ surface via single-atom metal doping. Energy Environ. Sci. 8, 1594 (2015). https://doi.org/10.1039/ C5EE00751H

39. Y. Wang, L. Chen, X. Yu, Y. Wang, G. Zheng, Superb alkaline hydrogen evolution and simultaneous electricity generation by Ptdecorated $\mathrm{Ni}_{3} \mathrm{~N}$ nanosheets. Adv. Energy Mater. 7, 1601390 (2017). https://doi.org/10.1002/aenm.201601390

40. H. Liao, C. Wei, J. Wang, A. Fisher, T. Sritharan, Z. Feng, Z.J. $\mathrm{Xu}, \mathrm{A}$ multisite strategy for enhancing the hydrogen evolution reaction on a nano-Pd surface in alkaline media. Adv. Energy Mater. 7, 1701129 (2017). https://doi.org/10.1002/aenm. 201701129

41. J. Xu, T. Liu, J. Li, B. Li, Y. Liu et al., Boosting the hydrogen evolution performance of ruthenium clusters through synergistic coupling with cobalt phosphide. Energy Environ. Sci. 11, 1819-1827 (2018). https://doi.org/10.1039/C7EE03603E

42. M. Gong, W. Zhou, M.C. Tsai, J. Zhou, M. Guan et al., Nanoscale nickel oxide/nickel heterostructures for active hydrogen evolution electrocatalysis. Nat. Commun. 5, 4695 (2014). https:// doi.org/10.1038/ncomms5695

43. T.F. Jaramillo, K.P. Jørgensen, J. Bonde, J.H. Nielsen, S. Horch, I. Chorkendorff, Identification of active edge sites for electrochemical $\mathrm{H}_{2}$ evolution from $\mathrm{MoS}_{2}$ nanocatalysts. Science 317, 100-102 (2007). https://doi.org/10.1126/science.1141483

44. J. Hu, C. Zhang, L. Jiang, H. Lin, Y. An, D. Zhou, M.K.H. Leung, S. Yang, Nanohybridization of $\mathrm{MoS}_{2}$ with layered double hydroxides efficiently synergizes the hydrogen evolution in alkaline media. Joule 1, 383-393 (2017). https://doi.org/10.1016/ j.joule.2017.07.011

45. Y. Luo, X. Li, X. Cai, X. Zou, F. Kang, H.M. Cheng, B. Liu, Two-dimensional $\mathrm{MoS}_{2}$ confined $\mathrm{Co}(\mathrm{OH})_{2}$ electrocatalysts for 
hydrogen evolution in alkaline electrolytes. ACS Nano 12, 4565-4573 (2018). https://doi.org/10.1021/acsnano.8b00942

46. X. Zhang, Y. Liang, Nickel hydr(oxy)oxide nanoparticles on metallic $\mathrm{MoS}_{2}$ nanosheets: a synergistic electrocatalyst for hydrogen evolution reaction. Adv. Sci. 5, 1700644 (2018). https:// doi.org/10.1002/advs.201700644

47. J. Zhang, T. Wang, D. Pohl, B. Rellinghaus, R. Dong, S. Liu, X. Zhuang, X. Feng, Interface engineering of $\mathrm{MoS}_{2} / \mathrm{Ni}_{3} \mathrm{~S}_{2}$ heterostructures for highly enhanced electrochemical overallwater-splitting activity. Angew. Chem. Int. Ed. 55, 6702-6707 (2016). https://doi.org/10.1002/anie.201602237

48. P. Kuang, T. Tong, K. Fan, J. Yu, In situ fabrication of Ni-Mo bimetal sulfide hybrid as an efficient electrocatalyst for hydrogen evolution over a wide $\mathrm{pH}$ range. ACS Catal. 7, 6179-6187 (2017). https://doi.org/10.1021/acscatal.7b02225

49. K. Xu, H. Ding, M. Zhang, M. Chen, Z. Hao, L. Zhang, C. Wu, Y. Xie, Regulating water-reduction kinetics in cobalt phosphide for enhancing her catalytic activity in alkaline solution. Adv. Mater. 29, 1606980 (2017). https://doi.org/10.1002/adma. 201606980

50. J. Zhang, T. Wang, P. Liu, S. Liu, R. Dong, X. Zhuang, M. Chen, $\mathrm{X}$. Feng, Engineering water dissociation sites in $\mathrm{MoS}_{2}$ nanosheets for accelerated electrocatalytic hydrogen production. Energy Environ. Sci. 9, 2789-2793 (2016). https://doi.org/10.1039/ C6EE01786J

51. Z. Weng, W. Liu, L.C. Yin, R. Fang, M. Li et al., Metal/oxide interface nanostructures generated by surface segregation for electrocatalysis. Nano Lett. 15, 7704-7710 (2015). https://doi. org/10.1021/acs.nanolett.5b03709

52. Z. Zhu, H. Yin, C.T. He, M. Al-Mamun, P. Liu et al., Ultrathin transition metal dichalcogenide/3d metal hydroxide hybridized nanosheets to enhance hydrogen evolution activity. Adv. Mater. (2018). https://doi.org/10.1002/adma.201801171

53. X. Yu, J. Zhao, L.R. Zheng, Y. Tong, M. Zhang, G. Xu, C. Li, J. Ma, G. Shi, Hydrogen evolution reaction in alkaline media: alpha- or beta-nickel hydroxide on the surface of platinum? ACS Energy Lett. 3, 237-244 (2018). https://doi.org/10.1021/acse nergylett.7b01103

54. M. Zhou, Q. Weng, Z.I. Popov, Y. Yang, L.Y. Antipina, P.B. Sorokin, X. Wang, Y. Bando, D. Golberg, Construction of polarized carbon-nickel catalytic surfaces for potent, durable, and economic hydrogen evolution reactions. ACS Nano 12, 4148-4155 (2018). https://doi.org/10.1021/acsnano.7b08724
55. Y. Liu, Q. Li, R. Si, G.D. Li, W. Li et al., Coupling sub-nanometric copper clusters with quasi-amorphous cobalt sulfide yields efficient and robust electrocatalysts for water splitting reaction. Adv. Mater. 29, 1606200 (2017). https://doi.org/10.1002/adma. 201606200

56. J.X. Feng, J.Q. Wu, Y.X. Tong, G.R. Li, Efficient hydrogen evolution on $\mathrm{Cu}$ nanodots-decorated $\mathrm{Ni}_{3} \mathrm{~S}_{2}$ nanotubes by optimizing atomic hydrogen adsorption and desorption. J. Am. Chem. Soc. 140, 610-617 (2018). https://doi.org/10.1021/jacs.7b08521

57. C. Wei, Z.J. Xu, The Comprehensive understanding of $10 \mathrm{~mA}$ $\mathrm{cm}_{\text {geo }}^{-2}$ as an evaluation parameter for electrochemical water splitting. Small Methods (2018). https://doi.org/10.1002/smtd. 201800168

58. S. Sun, H. Li, Z.J. Xu, Impact of surface area in evaluation of catalyst activity. Joule 2, 1019-1027 (2018). https://doi.org/10. 1016/j.joule.2018.05.003

59. Z. Li, D. Wang, Y. Wu, Y. Li, Recent advances in the precise control of isolated single site catalysts by chemical methods. Natl. Sci. Rev. 5(5), 673-689 (2018). https://doi.org/10.1093/nsr/ nwy056

60. Y.P. Zhu, C. Guo, Y. Zheng, S.Z. Qiao, Surface and interface engineering of noble-metal-free electrocatalysts for efficient energy conversion processes. Acc. Chem. Res. 50, 915-923 (2017). https://doi.org/10.1021/acs.accounts.6b00635

61. Z. Xing, C. Han, D. Wang, Q. Li, X. Yang, Ultrafine Pt nanoparticle-decorated $\mathrm{Co}(\mathrm{OH})_{2}$ nanosheet arrays with enhanced catalytic activity toward hydrogen evolution. ACS Catal. 7, 7131-7135 (2017). https://doi.org/10.1021/acscatal.7b01994

62. Z. Wang, Z. Liu, G. Du, A.M. Asiri, L. Wang et al., Ultrafine $\mathrm{PtO}_{2}$ nanoparticles coupled with a $\mathrm{Co}(\mathrm{OH}) \mathrm{F}$ nanowire array for enhanced hydrogen evolution. Chem. Commun. 54, 810-813 (2018). https://doi.org/10.1039/C7CC08870A

63. Z. Wang, X. Ren, X. Shi, A. Asiri, L. Wang, X. Li, X. Sun, Q. Zhang, H. Wang, A platinum oxide decorated amorphous cobalt oxide hydroxide nanosheet array towards alkaline hydrogen evolution. J. Mater. Chem. A 6, 3864-3868 (2018). https://doi. org/10.1039/C8TA00241J

64. C. Wang, P. Zhang, J. Lei, W. Dong, J. Wang, Integrated 3d $\mathrm{MoSe}_{2} @ \mathrm{Ni}_{0.85} \mathrm{Se}$ nanowire network with synergistic cooperation as highly efficient electrocatalysts for hydrogen evolution reaction in alkaline medium. Electrochim. Acta 246, 712-719 (2017). https://doi.org/10.1016/j.electacta.2017.06.028 